Javier

Maseda

Rodríguez

Universidad de

Santiago de

Compostela

javier.maseda@usc.es

Recibido: 26.10.21

Aceptado: 25.11 .21

\title{
Obligaciones alimenticias y competencia judicial internacional: régimen del ejercicio de la autonomía de la voluntad
}

\section{Maintenance obligations and international jurisdiction: the choice of court rules}

Resumen: Análisis del régimen de ejercicio de la autonomía de la voluntad como criterio de competencia judicial internacional en materia de obligaciones alimenticias desde la óptica de los órganos jurisdiccionales de un Estado miembro de la Unión Europea enfrentados a una reclamación de alimentos. Estudio de la normativa reguladora de las cláusulas de elección de foro a favor de un órgano jurisdiccional de un Estado miembro del Reglamento (CE) núm. 4/2009 del Consejo, de 18 de diciembre de 2008, relativo a la competencia, la ley aplicable, el reconocimiento y la ejecución de las resoluciones y la cooperación en materia de obligaciones de alimentos. Elección expresa de foro: carácter restrictivo y prohibición de su ejercicio respecto de menores de 18 años, frente a la libertad de los regímenes reguladores anteriores al Reglamento 4/2009. Y sumisión tácita, conflictiva respecto de alimentos para menores de esa edad. Estudio de las cláusulas de elección de foro a favor de los órganos jurisdiccionales de un tercer Estado, que el Reglamento 4/2009 no regula y que genera mucha inseguridad jurídica. Y estudio de las cláusulas de elección de foro a favor de los órganos jurisdiccionales de un Estado de la EFTA sólo vinculado por el Convenio de Lugano de 30 de octubre de 2007 relativo a la competencia judicial, el reconocimiento y la ejecución de resoluciones judiciales en materia civil y mercantil, que el Reglamento 4/2009, de modo unilateral, sí regula y cuya necesaria integración con la regulación general de este Convenio genera mucha controversia.

Palabras clave: obligaciones alimenticias; competencia judicial internacional; elección de foro.
Abstract: This paper analyzes the choice of court rules as a ground of international jurisdiction in matters relating maintenance obligations from a European Union Member State's court perspective. Study of the rules governing the choice of court clauses in favor of a member state's court contained in the current Council Regulation (EC) n. 4/2009 of 18 December 2008 on jurisdiction, applicable law, recognition and enforcement of decisions and cooperation in matters relating to maintenance obligations. Express choice of court agreement: restrictive nature and prohibition of the exercise regarding minors under 18. And analysis of jurisdiction based on the defendant's appearance, conflictive in disputes relating to maintenance obligations towards a child under that age. Study of choice of court clauses in favor of a third State court, a situation not regulated by Regulation 4/2009, putting at legal risk certainty. And the study of choice of court clauses in favor of an EFTA State court is only bound by the Lugano Convention on jurisdiction and the recognition and enforcement of judgments in civil and commercial matters on 30 October 2007, unilaterally ruled by Regulation 4/2009. Whose necessary integration with the general rules of this Convention generates many conflictive situations.

Keywords: Maintenance obligations; international jurisdiction; choice of court rules. 
Consolidada en materias de corte propiamente patrimonial, la autonomía de la voluntad viene adquiriendo cada vez mayor peso en materias en las que tradicionalmente no estaba siendo operativa: la revisión del papel de la persona y de sus intereses en la sociedad contemporánea extiende la idea de libertad individual a ámbitos como el Derecho de familia o de sucesiones, también en lo que se refiere al Derecho internacional privado ${ }^{1}$. Es lo que se observa, por ejemplo, en los arts. 7 y 22 del Reglamento (UE) 2016/1103 del Consejo, de 24 de junio de 2016, por el que se establece una cooperación reforzada en el ámbito de la competencia, la ley aplicable, el reconocimiento y la ejecución de resoluciones en materia de regímenes económicos matrimoniales ${ }^{2}$, que permiten tanto la elección de foro como de ley aplicable en materia de régimen económico matrimonial. $O$, en el mismo sentido, esta vez en materia de sucesiones internacionales, en los arts. 5 y 22 del Reglamento (UE) 650/2012, del Parlamento y del Consejo, de 04 de julio de 2012, relativo a la competencia, la ley aplicable, el reconocimiento y la ejecución de las resoluciones y los actos auténticos en materia de sucesiones y a la creación de un certificado sucesorio europeo ${ }^{3}$.

Coherente con el carácter económico de una materia vinculada con el Derecho de familia, las obligaciones alimenticias no son una excepción ${ }^{4}$. Los distintos legisladores (europeo, convencional o doméstico) vienen operando con/introduciendo la autonomía de la voluntad en esta materia: en el ámbito menos habitual y más novedoso de la ley aplicable, como se refleja, por ejemplo, en un art. 8 del Protocolo de La Haya de 23 de noviembre de 2007 sobre la ley aplicable a las obligaciones alimenticias, que permite la designación de la ley aplicable; y, en lo que ahora interesa, reforzando su intervención en el ámbito más tradicional de la competencia judicial internacional (Bonomi, 2007, párr. $110)^{5}$. No en vano, y al igual que sucede en el resto de las materias, permitir el ejercicio de la autonomía de la voluntad en materia de obligaciones alimenticias refuerza la previsibilidad del órgano jurisdiccional competente, así como la seguridad jurídica, disminuyendo en consecuencia los costes de litigación internacional en tanto que las partes podrán seleccionar el Tribunal que más se ajuste a sus intereses materiales y económicos (Poillot-Peruzzetto, 2009, párr. III; Castellanos, 2017, p. 49). Del mismo modo, y aunque muchas veces no se evita la fragmentación, la autonomía de la voluntad facilita la ubicación en un único órgano jurisdiccional de todos los litigios que puede plantear una demanda de familia, siendo el epicentro las crisis matrimoniales, sobre las que pivota la custodia de menores, el régimen económico matrimonial y, en lo que ahora nos ocupa, los alimentos y la pensión compensatoria (Vargas, 2018, p. 333; Jiménez, 2017, p. 67).

Lo que vamos a hacer en este trabajo es estudiar régimen y problemática del ejercicio de la autonomía de la voluntad como criterio de competencia judicial internacional en materia de obligaciones alimenticias desde la óptica de los órganos jurisdiccionales españoles enfrentados a una reclamación de alimentos en tanto que

\footnotetext{
1 Sobre esta proyección, Moura y Rodríguez, 2016, pp. 89-93; Arenas, 2017, pp. 43-45.

2 DOUE 8/7/2016.

${ }^{3}$ DOUE 27/7/2012.

${ }^{4}$ Véase Vargas, 2012, p. 106, sobre la realidad de la proyección de la autonomía de la voluntad en la elección de ley y de foro en materia familiar en las relaciones intracomunitarias, además de su necesidad; o Ancel \& Muir-Watt, 2010, pp. 467-468, señalando las bondades de abrir su ejercicio en el Derecho de familia, aunque esta autonomía, tal como sucede con los alimentos, no tenga la amplitud propia de las materias patrimoniales.

${ }^{5}$ Sobre elección de foro y reconocimiento de sentencias, Villata, 2011, pp. 750-751; o Borrás \& Degeling, 2007 , párr. 455.
} 
operadores jurídicos de un Estado miembro de la Unión Europea (UE). Y lo vamos a hacer en tres situaciones posibles. Una primera (punto 1.), relativa a las cláusulas de elección de foro a favor de un órgano jurisdiccional de un Estado miembro y a partir del estudio de la normativa contenida en el actual régimen del Reglamento (CE) núm. 4/2009 del Consejo, de 18 de diciembre de 2008, relativo a la competencia, la ley aplicable, el reconocimiento y la ejecución de las resoluciones y la cooperación en materia de obligaciones de alimentos ${ }^{6}$, valorando el carácter restrictivo de su juego, el modo de su puesta en práctica, así como la prohibición de su ejercicio respecto de menores, sobre todo en tanto que contrasta con la libertad que presidía su ejercicio en el régimen anterior del Reglamento (CE) núm. 44/2001, del Consejo, de 22 de diciembre de 2000 , relativo a la competencia judicial, el reconocimiento y la ejecución de resoluciones judiciales en materia civil y mercantil). Todo ello, no sólo en lo relativo a la elección expresa de foro, también en lo que se refiere a la sumisión tácita, de régimen semejante a la normativa anterior y con las dudas que genera su juego respecto de los alimentos a menores (punto 4.). Además del análisis de la elección de los órganos jurisdiccionales de un Estado miembro, valora el trabajo, como decíamos, dos situaciones más, también desde la óptica de los operadores jurídicos de un Estado miembro que se enfrentan a una reclamación de alimentos. Una segunda (punto 2.), relativa al juego de las cláusulas de elección de foro a favor de los órganos jurisdiccionales de un tercer Estado (Chile, México, Estados Unidos, Marruecos...), que el Reglamento 4/2009 no contempla y que genera gran incertidumbre al operador jurídico del Estado miembro que se enfrenta a ella. Y otra tercera y final (punto 3.), relativa al juego de las cláusulas de elección de foro a favor de los órganos jurisdiccionales de un Estado de la EFTA sólo vinculado por el Convenio de Lugano de 30 de octubre de 2007 relativo a la competencia judicial, el reconocimiento y la ejecución de resoluciones judiciales en materia civil y mercantip, que el Reglamento 4/2009 sí regula, aunque de modo unilateral, lo que provoca importantes dudas a la hora de su necesaria integración con la regulación general de este Convenio ${ }^{9}$.

Aunque analizaremos estas cuestiones desde la óptica de los órganos jurisdiccionales de un Estado miembro que se enfrentan a una reclamación de alimentos, téngase en cuenta que, a los efectos del Reglamento 4/2009, el concepto de órgano jurisdiccional incluye asimismo a las autoridades administrativas de los Estados miembros competentes en materia de obligaciones alimenticias, siempre que ofrezcan garantías en lo que se refiere a su imparcialidad y al derecho de audiencia de las partes y siempre que sus resoluciones puedan ser objeto de recurso o revisión ante una autoridad judicial y tengan fuerza y efectos similares a los de la resolución de una autoridad judicial (art. 2.2 R. 4/2009).

\footnotetext{
${ }^{6}$ DOUE 10/1/2009.

${ }^{7}$ DOCE L núm. 12, 16/1/2001. Regulaba las obligaciones alimenticias el Convenio de Bruselas sobre competencia judicial y reconocimiento y ejecución de decisiones en materia civil y mercantil, de 27 de septiembre de 1968 (DOCE C 189, 28/7/1990) hasta su sustitución por el Reglamento 44/2001. La entrada en vigor el 30/1/2009 del Reglamento 4/2009 (aplicable tras el 18/6/2011) supuso la exclusión de los alimentos del Reglamento 44/2001 para incluirlos en el Reglamento 4/2009. Excluidos asimismo del Reglamento (UE) núm. 1215/2012, del Parlamento Europeo y del Consejo, de 12 de diciembre de 2012, relativo a la competencia judicial, el reconocimiento y la ejecución de resoluciones judiciales en materia civil y mercantil (DOCE L-351/1, 20/11/2012) como régimen que sucedió al Reglamento 44/2001 tras el 10/1/2015.

${ }^{8}$ DOUE L 339, 21/12/2007, que sustituye desde el 1/1/2010, para España, al Convenio de Lugano de 16 de septiembre de 1988 relativo a la competencia judicial, el reconocimiento y la ejecución de resoluciones judiciales en materia civil y mercantil (BOE 20/10/1994; DOCE L 319, 25/11/1988).

${ }_{9}^{9}$ Téngase en cuenta que la UE se adhirió al Convenio de La Haya de 30 de junio de 2005 sobre Acuerdos de Elección de Foro (Decisión del Consejo de 4/12/2014), firmado por China, Estados Unidos y Ucrania, y ratificado por Montenegro, México, Singapur, Dinamarca y Reino Unido, en vigor desde el 1/10/2015. No obstante, excluye de su ámbito de aplicación a "las obligaciones alimenticias" (art. 2.2.b CH 2005).
} 


\section{Sumisión expresa a tribunales de un Estado miembro: régimen del Reglamento 4/2009 de alimentos}

1.1. Posibilidad de elección de foro en materia de alimentos: el Reglamento 44/2001 (y antecedentes) como precedente

Siguiendo la estela del Reglamento 44/2001, que amparaba el ejercicio de la autonomía de la voluntad en sede de competencia judicial internacional en toda materia no sometida a una competencia exclusiva (y alimentos no lo estaba), y del mismo modo que lo hacía su antecedente, el Convenio de Bruselas de 1968, la normativa comunitaria del Reglamento 4/2009 permite la elección de un órgano jurisdiccional de un Estado miembro a la hora de resolver los litigios relativos a obligaciones alimenticias: el art. 4 R. 4/2009 dispone que

...las partes podrán convenir en que el órgano u órganos jurisdiccionales (...) de un Estado miembro sean competentes para resolver los litigios en materia de obligación de alimentos suscitados o que puedan suscitarse entre ellos...

Que el Reglamento 4/2009 siga la estela del Reglamento 44/2001 (y su antecedente) no significa, no obstante, que compartan una regulación semejante: el régimen de elección de foro del art. 4 R. 4/2009 difiere claramente del establecido en sus precedentes, básicamente, del art. 23 R. 44 (anterior art. 17 CB 1968). No sólo existen importantes diferencias en torno a la amplitud del ejercicio de la autonomía de la voluntad, más importante en el Reglamento 44/2001 y más limitada en el art. 4 R. 4/2009, como veremos más adelante, también en lo que respecta a los criterios espaciales de aplicación del art. 4 R. 4/2009. Y es que, y a diferencia del art. 23 R. 44, que exige para su operatividad la domiciliación en la UE de al menos una de las partes, la prórroga de competencia del art. 4 R. 4/2009 juega sin consideración de su domicilio, de manera que su eficacia es la misma respecto de demandante y demandado domiciliados en la UE, como en un tercer Estado (Villata, 2011, p. 748; Queirolo \& Schiano di Pepe, 2008, p. 381).

Con todo, y a pesar de sus diferencias manifiestas, la influencia del art. 23 R. 44 en la determinación del alcance del art. 4 R. 4/2009 es importante, sobre todo en cuanto al objetivo de interpretación uniforme de sus términos. Recuérdese que toda norma comunitaria debe recibir una interpretación autónoma en atención a los objetivos y sistema del instrumento en el que se incardina, apelando sólo en segundo término a los principios generales que se derivan de los ordenamientos jurídicos nacionales ${ }^{10}$. En tal sentido y con el objetivo de determinar el alcance del art. 4 R. 4/2009, nada impide acudir a la práctica comunitaria que interpreta los términos del art. $23 \mathrm{R}$. 44. No en vano el legislador comunitario habla de que, "con el fin de preservar los intereses de los acreedores de alimentos y de favorecer una buena administración de justicia en la Unión Europea, deberían adaptarse las reglas relativas a la competencia tal como dimanan del Reglamento (CE) 44/2001" (Considerando núm. 15 R. 4/2009), siendo sustituidas las disposiciones del Reglamento 44/2001 por aquéllas propias del Reglamento 4/2009 (Considerando núm. 44 R. 4/2009). Del mismo modo, y aunque el Reglamento 4/2009 se incardina temporalmente en la órbita del Reglamento 44/2001, la reforma del Reglamento 44/2001 que dio lugar al actual Reglamento 1215/2012 no debería impedir la posibilidad de recurrir al nuevo art. 25 R. 1215, y práctica correspondiente, en tanto que sustituto del art. 23 R. 44 y en todo aquello en lo que no sea incompatible con el art. 4 R. 4/2009.

\footnotetext{
10 Véase, por ejemplo, ap. 29 STJCE 15/2/2007, As. C-292/05, Lechouritou; ap. 19 STJCE 23/4/2009, As. C-167/08, Draka NK Cables; o ap. 12 STJCE 3/7/1997, As. C-269/95, Benincasa.
} 
Admitido el ejercicio de la autonomía de la voluntad y su extensión a litigios en materia de alimentos ya suscitados o que puedan suscitarse entre las partes en el futuro, la prórroga de la competencia puede articularse de manera general o territorial, esto es, nada impide a las partes la elección genérica de los Tribunales de un Estado miembro o bien de unos concretos Tribunales dentro de un Estado miembro, debiendo recurrir a la legislación procesal de cada Estado en el primero de los casos a fin de identificar el órgano jurisdiccional finalmente competente (Pesce, 2013, p. 134; Castellanos, 2017, p. 50). Téngase en cuenta que, coherente con el concepto autónomo de autoridad jurisdiccional que emplea el Reglamento 4/2009 y que abarca ambas jurisdicciones, cabe asimismo semejante comportamiento respecto de aquellos ordenamientos jurídicos donde el conocimiento de las causas alimenticias no corresponda sólo a las autoridades judiciales, también a las administrativas (Pesce, 2013, pp. 134-135).

1.2. Existencia de un acuerdo relativo a la elección de foro en materia de alimentos

En una línea distinta a los foros objetivos que aporta el Reglamento 4/2009, orientados a favor de la figura del acreedor como demandante de alimentos, el foro basado en la autonomía de la voluntad del art. 4 R. 4/2009 presupone la existencia de un acuerdo entre las partes relativo a la elección de foro cuando habla de que "las partes podrán convenir" (Vargas, 2012, p. 105). Nada dice el art. 4 R. 4/2009, en cambio, respecto de qué debe entenderse y cómo valorar la existencia de un acuerdo entre las partes dirigido a la selección de un Tribunal competente para resolver sus controversias en materia de alimentos.
En ausencia de respuesta expresa del legislador europeo en el Reglamento 4/2009, debe tenerse en cuenta lo dispuesto en el art. 25 R. 1215 cuando se remite al Derecho del Estado miembro cuyo Tribunal resulta elegido a la hora de verificar la existencia de un consenso entre las partes: el art. 25 R. 1215 proporciona una regla uniforme respecto de la determinación de la validez material del acuerdo cuando se remite al "Derecho de dicho Estado miembro"11. Cubre así este art. 25 R. 1215 una laguna legal existente en el anterior art. $23 \mathrm{R}$. 44 que, a nuestro entender, resulta de utilidad en orden a perfilar los contornos de la existencia de un acuerdo entre partes, permitiendo así la interpretación uniforme de este punto con independencia del Tribunal del Estado miembro que haya sido elegido. La incorporación final de esta regla uniforme al tenor del art. 25 R. 1215 permite superar aquellas reticencias iniciales que desaconsejaban su extensión respecto del art. 4 R. 4/2009 cuando la reforma del art. 23 R. 44 en los términos expuestos (y ahora actuales) era todavía una mera posibilidad y con base en el argumento de la redacción inequívoca del art. 4 R. 4/2009 y la línea de la jurisprudencia del Tribunal de Justicia (TJUE) existente hasta ese momento ${ }^{12}$. Como indicábamos, y al margen de que esta disposición se ajusta asimismo a lo dispuesto en el art. 5 del Convenio de La Haya de 30 de junio de 2005 sobre Acuerdos de Elección de Foro, la transformación del anterior art. 23 R. 44, incorporando una regla común que antes no existía, sí tuvo lugar. Y está claro que poder recurrir a esta regla común facilita la interpretación uniforme del art. 4 R. 4/2009 en este punto, de mayor complicación de disponer únicamente de la sola práctica del TJUE.

\footnotetext{
${ }^{11}$ Fernández y Sánchez, 2020, p. 81, indicando - asimismo - que la ley de este Estado miembro podrá considerar que la validez material de la cláusula se determine conforme a la lex fori, de partir de una calificación procesal, o por remisión a la lex contractus, si la calificación es material.

12 Véase, en este sentido, Abendroth, 2014, p. 464, que cuestionaba con base en los argumentos referidos esta posibilidad, si bien parecía dejar la puerta abierta a operar a partir de una regla conflictual uniforme en la medida en que la reforma del Reglamento 44/2001 se consolidase, como así fue finalmente a través del art. 25 R. 1215.
} 


\subsection{Límites}

1.3.1. Autonomía restringida: sólo ciertos Tribunales susceptibles de elección

De acuerdo con el art. 4 R. 4/2009, las partes pueden convenir la competencia del órgano jurisdiccional del Estado miembro en el que una de las partes tenga su residencia habitual o aquél del Estado miembro del que sea nacional una de las partes (art. 4.1.a y b R. 4/2009). De tratarse de una obligación de alimentos entre cónyuges o excónyuges, podrán acordar someter su controversia ante el órgano jurisdiccional competente para conocer de sus litigios en materia matrimonial, o bien ante aquél del Estado miembro en cuyo territorio tuvo la pareja su última residencia habitual común durante al menos un año (art. 4.1.c R. 4/2009).

No existe, pues, una libre elección de foro, sino, por el contrario, una libertad restringida: el margen de elección de foro se halla limitado materialmente a unos concretos órganos jurisdiccionales, identificados a partir de la residencia habitual o nacionalidad de cualquiera de las partes, o, en el caso de alimentos entre cónyuges o excónyuges, a partir de su última residencia habitual común o los foros matrimoniales, entrando en juego, en este caso, el Reglamento 2201/2003, sobre crisis matrimoniales ${ }^{13}$.

No extraña la elección de estos puntos de conexión como elementos de selección. Tanto la residencia habitual como la nacionalidad de cualquiera de las partes son criterios habituales en sede de Derecho de familia $y$, en particular, en materia de obligaciones alimenticias, del mismo modo que lo son la residencia habitual común de la pareja o el órgano jurisdiccional competente en materia matrimonial, también habituales en materia de obligaciones alimenticias, esta vez por su carácter accesorio a la causa matrimonial. No obstante, no define el Reglamento 4/2009 el concepto de residencia habitual, limitándose a establecer, tras indicar que la residencia habitual debe ser más estricta que la residencia, que "el criterio de residencia debería excluir la mera presencia" (Considerando núm. 32 R. 4/2009). Con todo, puede entenderse la residencia habitual como el lugar donde se sitúa el centro social efectivo de desarrollo de la vida de una persona: presencia física no ocasional o temporal del individuo en un Estado miembro, identificada a partir de criterios objetivos como duración y permanencia de la residencia, así como los vínculos familiares, profesionales y sociales (regularidad, grado de integración, conocimientos lingüísticos...) (Abendroth, 2014, p. 466; Andrae, 2010, párr. 27). Sigue esta definición la línea de la práctica comunitaria que perfila este concepto fáctico en otros instrumentos comunitarios de Derecho de familia como el Reglamento 2201/2003, siendo coherente además con las disposiciones del Convenio de La Haya de 2007 y perfectamente proyectable en materia de obligaciones alimenticias del Reglamento 4/2009 (Rodríguez, 2020, párr. 8; Calvo y Carrascosa, 2018, p. 545) ${ }^{14}$.

La nacionalidad debe determinarse, por su parte y a diferencia de la residencia habitual, a partir de las disposiciones domésticas de cada Estado, teniendo en cuenta su sustitución, a efectos del art. 4 R. 4/2009, por el criterio del domicile en aquellos Estados miembros que utilicen dicho concepto como criterio de vinculación en materia familiar (art. 2.3 R. 4/2009), básicamente, los Estados de tradición anglosajona, más relevante antes de la salida del Reino Unido de la UE tras el brexit't5.

\subsubsection{Fundamentación de la autonomía restringida}

Si bien no llama la atención, por las razones antes expuestas y como muestra de la extensión de la autonomía de la voluntad, la posibilidad de elección de

\footnotetext{
${ }^{13}$ Véase Walker, 2015, p. 65, cuando estima que esta limitación en la extensión de la autonomía de la voluntad del art. 4 R. 4/2009 debería prevenir erróneas elecciones de foro.

${ }^{14}$ En la práctica comunitaria, como muestra, por ejemplo, ap. 60 STJUE 15/1/2017, As. C-499/15, W, V. v. X; o ap. 46 a 49 STJUE 22/12/2010, As. C- 497/10, Mercredi.

${ }^{15}$ Sobre el concepto de domicile anglosajón, completamente distinto del concepto de domicilio continental (art. 40 Código Civil español, por ejemplo), véase Cheshire, North \& Fawcett, 2017; Dicey, Morris \& Collins, 2012; o Dutta, 2017, pp. 555-561.
} 
foro en materia de obligaciones alimenticias, sí lo hace el carácter restrictivo (o incluso, inexistente) de su regulación en el Reglamento 4/2009, sobre todo si lo comparamos con el tenor de la Propuesta de Reglamento 4/2009 en tanto que preveía la libre elección de jurisdicción ${ }^{16}$. Y más todavía si lo hacemos con la amplitud de su ejercicio en el anterior Reglamento 44/2001'17, en un contexto el de este instrumento en el que, no olvidemos, existían casos en los que se establecían restricciones a su juego en materias en las que también participaba una parte débil (Abendroth, 2014, p. 460).

Ausente motivación alguna en la normativa o en los Considerandos del Reglamento 4/2009 explicativa de este cambio de orientación, tiene que ver esta limitación con el peso de la figura del demandado dentro de una relación personal considerada estructuralmente desigual en orden a procurar la adecuada protección del acreedor de alimentos (Ancel \& Muir-Watt, 2010, pp. 466-467; Deschamps, 2011, p. 807) ${ }^{18}$. No tanto por el hecho de permitir la elección solo de los Tribunales de la residencia y/o nacionalidad del acreedor de alimentos en tanto que también se permite la elección de los órganos jurisdiccionales de la residencia y/o nacionalidad del deudor de alimentos, sino por la exigencia de una vinculación objetiva entre los Tribunales elegidos y la relación alimenticia (Pesce, 2013, p. 143, nota 52). La dimensión civil patrimonial con el que el Reglamento 44/2001 se enfrentaba a la obligación alimenticia aparece ahora sustituida en el Reglamento 4/2009 como régimen que desplaza a la anterior normativa por un enfoque estrictamente de Derecho de familia (Widiez, 2019, párr. 184; Poillot-Peruzzetto, 2009, párr. III) ${ }^{19}$. O, lo que es lo mismo, mientras que no limitar la autonomía privada puede tener su razón de ser en el ámbito de la disponibilidad de los derechos patrimoniales, vincular un Tribunal con una reclamación de alimentos sólo a partir del único ligamen de la voluntad de las partes tiene más difícil ajuste en el ámbito de las obligaciones alimenticias (Pesce, 2013, p. 133). Autonomía de la voluntad y restricciones a su ejercicio se emparentan así con "la naturaleza híbrida del concepto de obligación de alimentos, que es familiar por sus raíces, pero pecuniaria en su aplicación, como cualquier crédito"20, a lo que responde el Reglamento 4/2009 (y Protocolo 2007) en lo que es su vertiente familiar (obligaciones de alimentos derivadas de una relación familiar, de parentesco, matrimonio o afinidad) y el Reglamento 1215/2012 (o Roma I) en lo que afecta a su proyección patrimonial (obligaciones de alimentos derivadas de una relación contractual) (Vassalli, 2012, p. 363).

Situar los márgenes de esta limitación en los Tribunales de la nacionalidad, residencia habitual de las partes o foros matrimoniales, pretende garantizar la proximidad entre el Tribunal elegido y los hechos controvertidos a partir de la vinculación que el legislador europeo exige entre el órgano jurisdiccional susceptible de ser elegido y el litigio de alimentos (el Considerando núm. 19 R. 4/2009 habla de "factores de vinculación"), aspecto que un libre

\footnotetext{
${ }^{16}$ Véase el art. 4.1 de la Propuesta de Reglamento del Consejo relativo a la competencia, la ley aplicable, el reconocimiento y la ejecución de las resoluciones y la cooperación en materia de obligaciones de alimentos (COM [2005] 649 final). También, Walker, 2015, p. 66, comparando las limitaciones a la libre elección de foro del Reglamento 4/2009 con su amplitud desde la óptica del art. 20.1.e CH 2007. ${ }_{17}$ Véase Abendroth, 2014, p. 460 y p. 464, que califica como sorprendente la amplitud del juego de la elección de foro del Reglamento 44/2001 en materia de alimentos.

${ }^{18}$ Al hilo del Convenio de Lugano de 2007, cuya reglamentación de las cláusulas de elección de foro es semejante a la del Reglamento 44/2001 (también a la propia del Reglamento 1215/2012), Nylund, 2019, párr. 3.1, cuando se refiere, precisamente por la ausencia de restricciones en la elección de foro en el Convenio de Lugano, a la posibilidad de que un deudor bien informado seleccione el Tribunal más ajustado a sus intereses, en detrimento de la posición del acreedor de alimentos, o evite seleccionar aquel Tribunal menos conveniente para su reclamación.

${ }^{19}$ Véase, asimismo, Walker, 2015, pp. 65-66, calificando como problemático que originariamente haya tratado los alimentos una normativa como el Reglamento 44/2001 dirigida a materias ajenas al Derecho de familia.

${ }^{20}$ Véase Propuesta de Reglamento del Consejo relativo a la competencia, la ley aplicable, el reconocimiento y la ejecución de las resoluciones y la cooperación en materia de obligaciones de alimentos (COM [2005] 649 final), p. 8.
} 
ejercicio de autonomía de la voluntad no aseguraría ${ }^{21}$. Nada qué decir al respecto en cuanto a la conexión residencia habitual o Tribunal competente en materia de crisis matrimoniales. Sin duda, estos Tribunales se hallan en la mejor posición a la hora de evaluar las condiciones de vida de acreedor y/o deudor al responder a las necesidades del dependiente y a las capacidades del deudor. O, como es el caso de los Tribunales competentes en materia matrimoniales, pueden responder de modo más adecuado a la controversia alimenticia desde la óptica de unos órganos jurisdiccionales que tienen una visión de conjunto sobre la realidad de las partes al asumir las disputas de alimentos y todas las causas relacionadas. No parece ser así, en cambio, en cuanto a la conexión nacionalidad, cuestionable desde la óptica de la proximidad. Si bien es cierto que nacionalidad de un Estado suele coincidir muchas veces con residencia y/o domicilio en tal Estado, no siempre es así, lógicamente, y menos en los casos que ahora nos ocupan de tráfico privado externo: en materia de obligaciones alimenticias, la nacionalidad no es siempre representativa de un vínculo particularmente estrecho entre las personas involucradas y un concreto Estado miembro (Pesce, 2013, p. 133, nota 38; Lipp, 2013, párr. 22; Abendroth, 2014, p. 465). No contribuye a esta garantía de proximidad, ni respecto de la conexión nacionalidad como tampoco respecto de la residencia habitual, el hecho de que el legislador europeo considere el cumplimiento de estas condiciones, además de en el momento de presentarse la demanda, "en el momento de celebrarse el convenio relativo a la elección del foro" (art. 4.2 R. 4/2009). Siendo esto así, nada impide que los factores de conexión que implican la proximidad sean otros habida cuenta del posible transcurso del tiempo entre este punto de referencia temporal y el momento en el que se desarrolla el proceso de alimentos. La referencia temporal condicionante de la validez de la cláusula de elección de foro puede reducir así, en ciertos casos, la vinculación efectiva con el órgano jurisdiccional seleccionado: la cláusula será válida, si bien puede no corresponderse ya con las necesidades de una o ambas partes (Villata \& Válková, 2020, p. 639, nota 21; Abendroth, 2014, p. 465). Es lo que sucede, por ejemplo, respecto de la elección del Tribunal de la nacionalidad de una de las partes, posteriormente perdida y no coincidente ni con la nacionalidad de la otra parte ni con la residencia habitual de ninguno de los dos (Álvarez, 2009, párr. V.II; Villata \& Válková, 2020, p. 639, nota 21 in fine). $Y$ es que, presidido por el favor validitatis, que el legislador europeo permita verificar esta vinculación tanto en el momento de conclusión del acuerdo como en el momento de la reclamación de los alimentos da muestra de la irrelevancia de un cambio de residencia habitual de las partes o de una modificación de su nacionalidad (Castellaneta \& Leandro, 2009, p. 1071), lo que no sólo va a permitir que un acuerdo privado de vinculación con las partes en un primero momento pueda, en una suerte de validez sobrevenida, subsanarse a la hora de demanda porque allí sí concurra, también admite lo contrario: que un acuerdo sí vinculado con las partes en un primer momento no lo esté posteriormente (Pesce, 2013, p. 135; Villata \& Válková, 2020, p. 639, nota 21$)^{22}$.

Nada impide designar un concreto órgano jurisdiccional competente de acuerdo con las posibilidades concedidas por el art. 4.1 R. 4/2009 mientras esta circunstancia se verifique en el momento de la conclusión del acuerdo o en el momento en el que se reclama ante el Tribunal. También es posible seleccionar con carácter general un órgano jurisdiccional, de verificarse esta circunstancia, al igual que antes, en el momento de la conclusión del

\footnotetext{
${ }^{21}$ Pesce, 2013, p. 133, sobre la dificultad para valorar la situación patrimonial de acreedor y deudor de alimentos de un Tribunal elegido alejado de las circunstancias de vida de las partes.

22 Pesce, 2013, p. 135, poniendo esto de manifiesto, así como la ausencia en el Reglamento 4/2009 de pautas para resolver estas situaciones controvertidas derivadas del juego de los dos momentos relevantes, dejando este autor en manos del juez el examen de la verdadera voluntad de las partes.
} 
acuerdo o en el momento en el que se reclama ante el Tribunal: puede formularse a modo de "residencia habitual de la parte A/parte B en el momento en el que se accione ante el Tribunal" (Villata \& Válková, 2020, p. 639, nota 21). Supondrá que el Tribunal competente podrá ir cambiando en el transcurso del tiempo. Del mismo modo, tal como ya mencionamos, y en atención al favor validitatis que preside este precepto, puede designarse un Tribunal de un Estado miembro que, en el momento del acuerdo, no se halle en el listado de opciones del art. 4.1 R. 4/2009: será perfectamente válido de figurar más tarde dentro de las posibilidades ofrecidas por este art. 4 R. 4/2009. O, lo que es lo mismo, podría ajustarse al art. 4 R. 4/2009 un acuerdo a favor de los Tribunales de la residencia habitual del deudor de alimentos, sin determinación del momento temporal relevante, aun cuando este deudor haya modificado su residencia ${ }^{23}$. Asimismo, puede apelarse al favor validitatis para resolver las dudas que pueden surgir respecto del momento temporal de referencia en aquellos casos en los que el acuerdo de elección de foro se manifiesta en la forma de selección del Tribunal de la residencia y/o nacionalidad del deudor y/o acreedor, pero sin mencionar ningún Estado miembro (u órgano jurisdiccional) concreto (por ejemplo, acuerdo a favor de los Tribunales de residencia del acreedor de alimentos, residiendo este acreedor en España en el momento del acuerdo y en Italia en el momento de la litis): supondría la competencia de ambos Tribunales. En cualquier caso, parece aconsejable referir el momento temporal al que hace referencia la cláusula de elección de foro (Villata \& Válková, 2020, p. 639, nota 21).

No debe descartarse que detrás de las conexiones nacionalidad y residencia habitual se encuentre, más ajustadamente, la idea de evicción del abuso de Derecho en el ejercicio de la autonomía de la voluntad en lo relativo a las cláusulas de elección de foro y determinante de muchas de las acciones del legislador europeo enfrentado a la participación de una parte débil ${ }^{24}$. De ser así, la vinculación entre acreedor y deudor de alimentos respecto del órgano jurisdiccional seleccionado derivada de la conexión nacionalidad o residencia habitual de cualquiera de las partes no tendría como finalidad la proximidad de la causa alimenticia con el Tribunal, sino garantizar la estabilidad y previsibilidad de la sumisión realizada (Álvarez, 2009, párr. V.II). Lo expuesto permitiría generar la seguridad suficiente al eventual acreedor de alimentos, reforzando su posición como parte más vulnerable al poder elegirse sólo Tribunales vinculados objetivamente en un momento dado a las partes de la relación. Desde esta óptica, y además del elemento residencia habitual, que responde también, como vimos, a la idea de proximidad, se justificaría la idoneidad de la conexión nacionalidad, así como el mandato del legislador europeo de situar temporalmente estas condiciones en el momento en que se concluye el acuerdo de elección de foro o en el momento en que se lleva a cabo el juicio (Lipp, 2013, párr. 23).

Sigue así la línea del legislador europeo en otras materias donde se prevé la participación de una parte más vulnerable, tal como sucede con los trabajadores, los consumidores, los asegurados o tomadores de seguros, donde, con distintas técnicas y dada su situación de asimetría estructural, también se limita el ejercicio de la autonomía de la voluntad en relación con la elección de foro precisamente para proteger a esta parte débil (Virgós y Garcimartín, 2007, pp. 296-297). Sirva el caso de los contratos individuales de trabajo, respecto de los cuales sólo se hallan permitidas las cláusulas de elección de foro "posteriores al nacimiento del litigio, o que permitan al trabajador formular demandas ante

\footnotetext{
${ }^{23}$ Lo cuestiona, sin embargo, Villata \& Válková, 2020, p. 639, nota 21.

${ }^{24}$ Abendroth, 2014, pp. 465-466, que considera interpretar esta restricción como un control institucionalizado del abuso. Véase, asimismo, Vargas, 2012, p. 105, que habla de estas limitaciones o cautelas como la respuesta a los posibles recelos de los Estados miembros ante la extensión de la autonomía de la voluntad en materias tan sensibles como las obligaciones alimenticias.
} 
órganos jurisdiccionales distintos de" los foros objetivos que ya disfruta.

\subsubsection{Doble nacionalidad de la(s) parte(s)}

En cualquier caso, este carácter restrictivo que preside este art. 4.2 R. 4/2009 se limita a lo dispuesto en el tenor del precepto, esto es, no justifica mantener por principio una interpretación restrictiva en aquellos supuestos no expresamente contemplados. Lo vemos en el caso de los dobles nacionales. Coherente con la libertad que preside el ejercicio de la autonomía de la voluntad, una doble nacionalidad permitiría a las partes la selección de los órganos jurisdiccionales del Estado miembro de cualquiera de las nacionalidades que ostente el doble nacional (Widiez, 2019, párr. 185; Abendroth, 2014, p. 466 y referencias $)^{25}$. A nuestro entender, se ajusta mejor esta respuesta a los principios propios de la autonomía de la voluntad que la opción de operar sólo a partir de una nacionalidad preferente determinada por la legislación correspondiente, normalmente, por Tratados de doble nacionalidad o, en su defecto, por normativa interna.

1.3.4. Alimentos entre cónyuges y excónyuges: regla especial o regla alternativa en materia de elección de foro

Lo mismo puede decirse en cuanto a las obligaciones alimenticias entre cónyuges o excónyuges. A pesar del tenor del art. 4.2.c R. 4/2009 y aunque nada se dice en los trabajos preparatorios del Reglamento 4/2009, la mejor interpretación pasa por considerar esta potencial competencia prorrogada en materia de alimentos por razón del matrimonio como competencia de carácter accesorio a la recogida en los dos supuestos anteriores del art. 4.1.a y b R. 4/2009 (Álvarez, 2009, párr. V.Il; Deschamps, 2011, p. 808; Widiez, 2019, párr. 186; Villata \& Válková, 2020, p. 637, nota 20). Es cierto que el legislador europeo habla específicamente de "por lo que respecta a las obligaciones de alimentos entre cónyuges o excónyuges", lo que parece limitar la elección de foro relativa a los alimentos entre cónyuges o excónyuges a los órganos jurisdiccionales relacionados sólo en el punto c) del art. 4.1 R. 4/2009²6, esto es, al órgano jurisdiccional competente para conocer de sus litigios en materia matrimonial, o al órgano jurisdiccional del Estado miembro de su última residencia habitual común. También es cierto que una interpretación amplia de las opciones permitiría a los cónyuges o excónyuges seleccionar el Tribunal del Estado miembro de la nacionalidad de cualquiera de las partes sin limitación de tiempo, existiendo en cambio limitaciones temporales respecto de lo que son propiamente las opciones que el legislador concede a la pareja (exigencia de al menos un año en relación con su última residencia habitual común, por ejemplo), lo que puede ser un indicio a favor de una interpretación restrictiva de las opciones ${ }^{27}$. No contribuye tampoco a aclarar el panorama el hecho de que el legislador europeo haya empleado una terminología diferente en los distintos apartados del art. 4. R. 4/2009: frente a un art. 4.1. a y b R. 4/2009 en el que habla de partes, hace referencia sólo a cónyuges y excónyuges en el art. 4.1.c R. 4/2009²8.

A nuestro entender, no obstante, no cabe una interpretación restrictiva de este precepto ya restrictivo. Primero, porque no tiene sentido que el legislador europeo haya restringido todavía más y sin mayor explicación el ejercicio de la elección de foro en el ámbito de los alimentos entre cónyuges y excónyuges donde surgen la mayoría de las controversias. Segundo, porque no casa esta restricción con el principio de libertad que preside el ejercicio de la autonomía de la voluntad, lo que resultaría

\footnotetext{
${ }^{25}$ Así parece entenderlo también, Ancel \& Muir-Watt, 2010, p. 467, nota 40.

${ }^{26}$ Abendroth, 2014, p. 467, sobre la manera concluyente en la que parece estar redactado el art. 4.1.c R. 4/2009.

${ }^{27}$ Apunta la duda, Widiez, 2019, párr. 186.

${ }^{28}$ Mãrculescu, Filip Radu \& George, 2016, párr. II.2.2, cuestionándose la trascendencia de este cambio de términos: si se pretendía interpretar que todas las partes (término que excluiría a los cónyuges) pueden elegir entre los Tribunales incluidos en la letra a y b, limitándose los cónyuges a los Tribunales incluidos en la letra c; o era intención del legislador permitir que cualquier parte (incluidos los cónyuges) pudiera elegir los Tribunales de las letras a y b, y, además, conceder a los cónyuges más opciones (opciones que no están disponibles para otras partes, excepto ellos); estos autores abogan por esta última interpretación.
} 
contradictorio con lo proclamado en el Considerando núm. 19 del Reglamento 4/2009 cuando habla de previsibilidad y autonomía de las partes como elementos justificantes de la cuestión de la elección de foro (Andrae, 2010, párr. 40 y 42; Abendroth, 2014, p. 467). Y, tercero, porque provocaría una desigualdad de trato no fundamentada en razones objetivas y en contra de este principio tal como se halla recogido en el Considerando núm. 11 del Reglamento 4/2009 cuando, después de referirse a "todas las obligaciones de alimentos derivadas de las relaciones familiares, de parentesco, matrimonio o afinidad", habla de "garantizar la igualdad de trato de todos los acreedores de alimentos". En tal sentido, nada debería impedir que los cónyuges o excónyuges puedan seleccionar los Tribunales del Estado miembro de su nacionalidad común, que podría venir introducido a partir del art. 4.1.c.i R. 4/2009 a título de "órgano jurisdiccional competente para conocer de sus litigios en materia matrimonial" (el art. 3 R. 2201 contempla este foro para las crisis matrimoniales), del mismo modo que también podrían seleccionar los Tribunales del Estado miembro de la nacionalidad no común de uno u otro. No estamos de acuerdo, pues, en la consideración del art. 4.1.c R. 4/2009 como una regla especial frente a otra general del art. 4.1.a y b R. 4/2009, que pueda llevar a rechazar la posibilidad de que los cónyuges elijan los Tribunales del Estado miembro de la nacionalidad de cualquiera de ellos, aunque no residan en la UE y ello conduzca a una dispersión del pleito en materia matrimonial29.

Al hilo de lo expuesto, téngase en cuenta que esta competencia prorrogada relativa a las obligaciones alimenticias entre cónyuges y excónyuges, operativa dentro de la totalidad de opciones que ofrece el art. 4.1 R. 4/2009, no debería referirse exclusivamente los litigios de alimentos entre los miembros de una pareja en su calidad de cónyuges y excónyuges, también debería comprender los supuestos de alimentos debidos por razón de la nulidad del matrimonio, con independencia de la calificación o no de excónyuges para los interesados (Álvarez, 2009, párr. V.II).

1.4. Alimentos para menores: inoperatividad de la elección expresa de foro

Además de la limitación entre los órganos jurisdiccionales a elegir y con la intención de garantizar la protección de la parte más débili ${ }^{30}$, el legislador europeo prohíbe el ejercicio de la sumisión expresa en los litigios relativos a la obligación de alimentos respecto de menores en los términos de que "el presente artículo no es aplicable a los litigios relativos a la obligación de alimentos respecto de un menor de edad inferior a 18 años" (art. 4.3 R. 4/2009) ${ }^{31}$, concordante también con la respuesta del Protocolo 2007 en materia de ley aplicable en tanto que prohíbe la elección de ley en los mismos supuestos (art. 8 Protocolo 2007). La inoperatividad de un acuerdo de elección de foro en estas circunstancias supone operar exclusivamente a partir de los foros determinados por el art. 3 R. 4/2009; no excepciona, pues, la aplicación de un art. 3 R. 4/2009 basado precisamente en la protección de la parte débil a partir de criterios exclusivamente objetivos (tampoco de los arts. 6, 7 u 8 R. 4/2009) (Pesce, 2013, p. 139). Considerado incapaz desde la óptica del Derecho civil de los contratos, la inhabilitación del consentimiento del menor tiene su base en su vulnerabilidad a la presión que el deudor de alimentos podría ejercer en una relación de parentesco (deudores, parientes, tutores...) (Ancel \& Muir-Watt, 2010, p. 467; Deschamps, 2011, p. 809; Villata, 2011, p. 749).

\footnotetext{
${ }^{29}$ En otro sentido, Vargas, 2018, pp. 333-334.

${ }^{30}$ Véase, así, la Comunicación de la Comisión al Consejo y al Parlamento Europeo (Comentarios sobre los artículos de la propuesta de Reglamento del Consejo sobre la competencia, la ley aplicable, el reconocimiento y la ejecución de las resoluciones judiciales y la cooperación en materia de obligaciones de alimentos), COM (2006) 206 final, p. 3, sobre esta protección de la parte débil. Sobre el alimentista como parte más débil de la relación, véase ap. 28 STJUE 18/12/2014, As. C-400/13 y As. C-408/13, Sanders.

${ }^{31}$ Beaumont, 2009, p. 533, en relación con el Convenio de La Haya de 2007. En la práctica, por ejemplo, Sent. Trib. Brezno 28/8/2013 (2P/93/2013, SKF20130828; referido en: Gandía, Faucon \& Siaplaouras, 2020, p. 182, nota 113), mencionando el Tribunal la inoperatividad de una cláusula de elección de foro respecto de menores de 18 años.
} 
La minoría de edad determinada por los 18 años justifica así la prohibición de dar efecto a un acuerdo de elección de foro relativo a los alimentos de este menor, aun cuando este menor se hallase en condiciones de poder asumir las consecuencias legales del acuerdo por el hecho de que, según su Derecho nacional, dispusiese de capacidad plena o parcialmente plena (sujetos emancipados, por ejemplo) (Pesce, 2013, p. 140; Andrae, 2010, párr. 50). Del mismo modo, es la minoría de edad la que marca el límite de la validez del acuerdo de elección de foro por razones de capacidad, lo que supone la operatividad de la cláusula respecto de mayores de 18 años, aun cuando no pueda decirse que estos adultos jóvenes no sean merecedores asimismo de protección en tanto que siguen siendo la parte más débil frente a sus padres $u$ otros tutores que están pagando por su educación o mantenimiento, lo que pone en cuestión el equilibrio de un acuerdo sobre la jurisdicción que sea de su interés ${ }^{32}$.

$\mathrm{Si}$, de acuerdo con las disposiciones del Reglamento 4/2009, no existe duda de la inoperatividad de un acuerdo de elección de foro referido claramente a las obligaciones alimenticias relativas a un menor de 18 años, más problemas cuando la interpretación de su objeto no resulta clara, sabiendo que el art. 4.3 R. 4/2009 no regula la capacidad y que se limita exclusivamente a establecer la inaplicabilidad de este precepto a menores de esta edad. Piénsese en aquel caso relativo a un acuerdo de elección de foro, que, redactado en términos generales y en atención a los elementos a valorar (partes involucradas, momento de la celebración del acuerdo...), se refiere a la manutención general de un hijo. En este contexto, nada impide pensar que este acuerdo podría cubrir la manutención de un hijo antes y después de los 18 años (Abendroth, 2014, p. 468). La referencia a la obligación de alimentos respecto de un menor de edad inferior a 18 años permitiría justificar la nulidad de la totalidad de la cláusula (Andrae, párr. 51). Si bien es cierto que podría apelarse a una eventual nulidad parcial (Lipp, párr. 11), son muchos los riesgos para la parte débil inherentes al uso de un acuerdo incompleto o impreciso. Basándose en la validez del acuerdo, podría la parte débil comparecer ante un órgano jurisdiccional cuya selección resulta al menos parcialmente inválida, declarándose finalmente competente en caso de comparecencia y no impugnación por sumisión tácita (art. 5 R. 4/2009). Piénsese que la sumisión tácita resulta plenamente operativa también respecto de menores, ausente asimismo obligación alguna por parte de los Tribunales de informar a la parte de las consecuencias de una comparecencia sin impugnación de la competencia (Abendroth, 2014, pp. 468-469). Todo ello aconseja como mejor respuesta la invalidez de la totalidad del acuerdo en aras a la protección integral del menor, además de mostrar la conveniencia de una redacción precisa de la cláusula (Abendroth, 2014, p. 469).

En cualquier caso, y aunque no deja lugar a dudas el legislador europeo respecto de la inaplicación de un acuerdo de elección de foro respecto de los alimentos debidos a un menor de 18 años, llama la atención que esta limitación sea absoluta y que no haya posibilidad de utilizar la cláusula de sumisión expresa en aquellos casos en los que el acuerdo respete los intereses del menor acreedor de alimentos ${ }^{33}$. O, lo que es lo mismo, que no se hayan dejado fórmulas que permitan su utilización de ser ventajoso para el menor, tales como conceder al foro elegido carácter no exclusivo, condicionar su validez a la verificación de que la cláusula favorece al menor o de atribuírsele exclusivamente al menor la facultad de hacer uso de este acuerdo (Pocar, 2009, p. 9; Pocar \& Viarengo, 2009, p. 814). No sería imposible. Por un lado, porque el legislador europeo recoge otros casos en los que, partiendo asimismo de la existencia de un desequilibrio estructural entre los participantes, sí opera

\footnotetext{
32 Al respecto, Corrao, 2011, p. 129; también, si bien más centrado en el Convenio de La Haya de 2007, Beaumont, 2009 , p. 533.

${ }^{33}$ De esta opinión, además de Pocar, 2009, p. 9; Castellaneta \& Leandro, 2009, p. 1071; o Ferrand, 2011, p. 95; también, Hellner, 2008, p. 349; o Castellanos, 2017, p. 51, que entiende criticable una restricción tan rígida.
} 
el acuerdo de elección de foro en aquellos supuestos en los que su utilización beneficie a la parte más débil. Sería el caso, por ejemplo y como ya vimos, de una cláusula de elección de foro en un contrato individual de trabajo y anterior al nacimiento del litigio, de imposible utilización por el empresario y plenamente operativa de beneficiar al trabajador, lo que sucedería cuando permita al trabajador formular demandas ante órganos jurisdiccionales distintos de los foros objetivos que ya disfruta (art. 23 R. 1215). Y, por otro, porque no se apreció problema alguno en la práctica respecto del funcionamiento de las cláusulas de elección de foro cuando las obligaciones alimenticias estaban incluidas en su ámbito de aplicación del menos restrictivo art. 23 R. 44 (Hellner, 2008, p. 349). Con todo, y a pesar de lo expuesto, la terminología es clara en cuanto a la inaplicación de este tipo de acuerdos de elección de foro respecto de los alimentos de menores de 18 años, no ayudado tampoco por el contexto de las dudas existentes entre muchos de los Estados miembros respecto del juego de la autonomía de la voluntad en materia de obligaciones alimenticias.

Por otra parte, y visto lo visto respecto de los alimentos relativos a menores de 18 años, no se entiende la operatividad de este tipo de acuerdos respecto de adultos incapacitados o vulnerables (Corrao, 2011, p. 129). Más todavía cuando su exclusión sí fue propuesta por el Parlamento Europeo en sus enmiendas y cuando el Protocolo 2007 sí extiende la inaplicación del precepto que regula la designación de la ley aplicable "a un adulto que, por razón de una disminución o insuficiencia de sus facultades personales, no se encuentra en condiciones de proteger sus intereses" (art. 8 Protocolo 2007).

\subsection{Forma del acuerdo de elección de foro}

Respecto de las exigencias de forma relativas al acuerdo de elección de foro, el art. 4.2 R. 4/2009 dispone que "el convenio (...) se celebrará por escrito", entendiéndose "hecho por escrito toda transmisión efectuada por medios electrónicos que proporcione un registro duradero del acuerdo".

Sigue así el legislador europeo la línea restrictiva marcada en este Reglamento 4/2009, ahora en materia de forma, en comparación con las reglas más flexibles del régimen anterior del art. 23 R. 44. Sólo admite como forma válida, pues, la celebración por escrito del acuerdo de elección de foro, lo que supone inadmitir como forma válida, por ejemplo, una celebración verbal con confirmación escrita (Castellaneta \& Leandro, 2009, p. 1072; Rodríguez, 2010, p. 12). Que ello sea así se debe no sólo a la intención del legislador europeo de garantizar fehacientemente la existencia del acuerdo en una materia en la que participa una parte débil, también a la escasa utilidad práctica en materia de obligaciones alimenticias de muchas de las opciones concedidas por el art. 23 R. 44. Ni la posibilidad de ajustarse a los hábitos que las partes tuvieren establecido entre ellas, ni aquélla otra de ajustarse, en el comercio internacional, a una forma conforme a los usos que las partes conocieren o debieren conocer y que, en dicho comercio, fueren ampliamente conocidos y regularmente observados por las partes en los contratos del mismo tipo en el sector comercial considerado, opciones que sí eran contempladas en el art. 23 R. 44, parecen alternativas útiles para acreedor y deudor de alimentos (Abendroth, 2014, p. 461; Castellaneta \& Leandro, 2009, p. 1072) ${ }^{34}$. Más utilidad práctica en obligaciones alimenticias podría tener la posibilidad de realizar un acuerdo oral con confirmación posterior escrita, opción también contemplada en el art. 23 R. 44 y no permitida en el actual art. 4 R. 4/2009, si bien también menos ajustada, sin duda, al objetivo de garantizar fehacientemente la existencia del acuerdo que veíamos antes.

En cualquier caso, en tanto que el Reglamento 4/2009 no contiene una definición de "por escrito" y que no cabe

${ }^{34}$ Por su parte, Pesce, 2013, p. 132, también incluye como modos poco ajustados a la práctica del Derecho de familia la forma oral con confirmación escrita posterior. 
una interpretación gramatical centrada en la redacción de esta disposición (Abendroth, 2014, p. 462), resulta útil el recurso a la práctica comunitaria interpretativa del alcance del art. 23 R. 44, no siendo posible ampararse en las definiciones domésticas relativas al concepto de forma escrita ${ }^{35}$. De acuerdo con ello, desde el momento en que el legislador europeo habla sólo de "por escrito" y aunque pudieran ser aconsejables a efectos probatorios, no serían necesarios requisitos complementarios o adicionales, tales como una firma de las partes o un documento contractual uniforme ${ }^{36}$. No es relevante, en este sentido, lo dispuesto en el Convenio de La Haya sobre el cobro internacional de alimentos y otras formas de manutención familiar de 23 de noviembre de 2007, cuyo art. 3.d CH 2007 define "acuerdo por escrito" en un sentido distinto y más limitado respecto del referido en el Reglamento 44/2001, en este caso, como "un acuerdo registrado en cualquier soporte cuyo contenido sea accesible para su ulterior consulta". Aunque el propio Reglamento 4/2009 establece que "estos (...) instrumentos (Convenio de La Haya de 2007, en lo que ahora interesa), deben tenerse en cuenta en el marco del presente Reglamento (4/2009)" (Considerando núm. 8 R. 4/2009), lo cierto es que la redacción del art. 4.2 R. 4/2009 no impone tal requisito en relación con el término legal "por escrito" allí empleado (Andrae, 2010, párr. 14). Por ello, tiene poco sentido asumir la definición de forma escrita del art. 3.d CH 2007 cuando el legislador europeo, conociendo esta norma, no la impuso en el marco de las obligaciones alimenticias del Reglamento 4/2009, y menos con base en ese (débil) tener en cuenta del que habla el Considerando núm. 8 R. 4/2009. De ahí que se hable del art. 4.2 R. 4/2009 como un precepto "elocuentemente silencioso" respecto de otros requisitos formales adicionales, no incluidos deliberadamente en su tenor (Abendroth, 2014, p. 463).

Tampoco un análisis de los objetivos del Reglamento
4/2009 respecto de las cláusulas de elección de foro parece justificar la exigencia de requisitos de forma adicionales. No lo parece desde la óptica del objetivo de incremento de la seguridad jurídica, la previsibilidad y la autonomía de las partes del que habla el Considerando núm. 9 R. 4/2009: preservar la autonomía de las partes pasa mejor por la no exigencia de requisitos no solicitados por la norma (Lipp, 2012, p. 860). Y tampoco desde la óptica de la protección de la parte débil: la existencia de una cláusula recogida por escrito que nace de un acuerdo entre las partes se ajusta plenamente a su derecho a conocer tanto las consecuencias de sus acciones, como el alcance de sus derechos y deberes, evitando una eventual incorporación unilateral que pueda ser ignorada por la contraparte (Abendroth, 2014, p. 463).

La consideración de hecho por escrito como "toda transmisión efectuada por medios electrónicos que proporcione un registro duradero del acuerdo", recogida en el art. 4.2 R. 4/2009, debe ser interpretada, asimismo, bajo los parámetros del art. 23 R. 44 (y del actual art. 25.2 R. 1215), que también lo recoge, a diferencia de lo que venía dispuesto en el art. 17 CB 1968. Supondría, por ejemplo, la validez formal de un acuerdo suscrito a través de un correo electrónico (Beaumont, 2009, p. 533, nota 52). La formulación amplia de esta indicación resulta adecuada a la hora de integrar como forma escrita una pluralidad de posibles herramientas de comunicación, hoy muchas veces telemáticas, capaces de registrar el acuerdo de modo duradero y de satisfacer los mínimos requisitos necesarios para poner de manifiesto su existencia (Pesce, 2013, pp. 131-132).

Pudiendo el acuerdo de elección de foro recogerse por escrito en un documento ad hoc autónomo, o bien como una cláusula dentro del clausulado de un contrato (de validez no condicionada a la validez del resto de cláusulas de ese contrato), téngase en cuenta que la

\footnotetext{
${ }^{35}$ Véase Abendroth, 2014, p. 462, y bibliografía allí referida, rechazando la posibilidad del acudir al art. 126 BGB alemán a la hora de definir el término por escrito del art. 4.2 R. 4/2009.

${ }^{36}$ Villata \& Válková, 2020, p. 643, consideran aconsejable registrar el acuerdo en un documento firmado por las partes involucradas; Abendroth, 2014, p. 462, y bibliografía a la que se remite.
} 
inobservancia de la exigencia formal de su celebración por escrito conlleva la inexistencia del acuerdo y la no producción de efectos legales: a diferencia del régimen del art. 23 R. 44, en el cual las exigencias de forma tenían carácter probatorio, desde la óptica del Reglamento 4/2009 su naturaleza es ad solemnitatem (Pesce, 2013, p. 132; Pocar, 2009, pp. 10-11; Castellanos, 2017, p. 51).

\subsection{Efectos de una cláusula de elección de foro}

1.6.1. Competencia exclusiva de los órganos jurisdiccionales elegidos: cláusulas de jurisdicción facultativas y cláusulas asimétricas en materia de alimentos

De acuerdo con lo dispuesto en el art. 4.1 in fine R. 4/2009, "la competencia atribuida por convenio será exclusiva", de manera que sólo los Tribunales elegidos serán los competentes para conocer de la reclamación de alimentos. O, lo que es lo mismo, y con la intención de aumentar la seguridad jurídica y la previsibilidad, la existencia de un acuerdo de elección de foro supondrá no sólo el efecto prorrogatio fori del órgano jurisdiccional seleccionado por la voluntad de las partes, también su efecto derogatio fori, convirtiendo en no competentes para conocer de los alimentos al resto de los Tribunales de los Estados miembros identificados a partir de los foros objetivos del Reglamento 4/2009 (Marino, 2009, pp. 604-605; Villata, 2011, p. 748; Rodríguez, 2010, p. 12).

No obstante, el término de exclusividad calificando la competencia de los órganos jurisdiccionales elegidos que emplea este art. 4 R. 4/2009 resulta equívoco, muy en la línea de un legislador europeo que no siempre emplea en el mismo sentido términos iguales, tal como sucede, por ejemplo, con la exclusividad de la que habla el art. $3 \mathrm{R}$. 2201, cuyos foros operan realmente de manera alternativa y no jerárquica, y no con base en un supuesto carácter privilegiado $^{37}$. Y es que la estricta exclusividad, que es propia de las competencias exclusivas de preceptos como el art. 24 R. 1215 y derivada de la naturaleza de las materias que incluye, implica la competencia única e inderogable de los Tribunales de un concreto Estado miembro, impidiendo que cualquier otra jurisdicción conozca del asunto. Y eso no sucede con la exclusividad del art. 4 R. 4/2009, desde el momento en que el legislador europeo, a pesar de la calificación que emplea respecto de la competencia atribuida por convenio y al igual que hace con el art. 25 R. 1215 (o su antecedente, el art. 23 R. $44^{38}$ ), condiciona su alcance a la existencia/ ausencia de un pacto en contrario entre las partes.

La referencia en el art. 4 R. 4/2009 a "salvo pacto en contrario entre las partes" quiebra la eventual competencia única e inderogable del órgano jurisdiccional seleccionado en todo caso. Por un lado, por la posibilidad de acreedor y deudor de alimentos de modificar un acuerdo expreso de elección de foro anterior a partir de la conclusión de un posterior acuerdo de elección de foro también expreso, así como por la posibilidad de proceder a la derogación de la competencia del Tribunal elegido por medio de la posterior comparecencia del demandado ante un Tribunal diferente sin la intención de impugnar su competencia (competencia por sumisión tácita del art. 5 R. 4/2009, como veremos). Y, por otro, y aunque reducen la previsibilidad del foro en los procedimientos de alimentos, por la posibilidad de incluir cláusulas de elección de foro facultativas (cláusulas de jurisdicción no exclusivas o híbridas) o convenios atributivos de jurisdicción en favor de una sola de las partes o estableciendo un distinto régimen de posibilidades a cada parte (cláusulas asimétricas). Las primeras no impiden la utilización de otros foros, permitiendo a las partes plantear su demanda de alimentos ante los Tribunales elegidos o ante los foros objetivos, facilitando

\footnotetext{
${ }^{37}$ Gaudemet-Tallon, 2001, p. 395, que se refiere a la exclusividad del art. 3 R. 2201 en un sentido menos exclusivo y sí limitativo del término, equivalente a la imposibilidad de operar con más foros de los referidos en el Reglamento 2201/2003.

${ }^{38}$ No así con el anterior art. 17 CB 1968, que hablaba más apropiadamente de "únicos competentes", más ajustado al verdadero alcance de la sumisión expresa que recoge.
} 
así la jurisdicción de un Tribunal que, de lo contrario, no tendría competencia ex art. 3 R. 4/2009 en el caso de que las partes cambien posteriormente su nacionalidad y/o residencia habitual. Las segundas, por su parte, pueden formularse en el sentido de que contemplen la elección exclusiva de Tribunal para una de las partes, conservando la otra, además del foro elegido, los foros objetivos (Villata \& Válková, 2020, pp. 640-641)39; o bien que la cláusula juegue solo a favor de una de las partes, decidiendo el favorecido emplear la cláusula o acudir a los foros objetivos. A pesar de las reticencias de cierta práctica en los Estados miembros negando validez a las cláusulas asimétricas unilaterales, no debería negarse a las partes la posibilidad de concluir un acuerdo asimétrico opcional de elección de foro en materia de alimentos, siempre y cuando respeten el favor creditoris que preside la regulación del Reglamento 4/2009, esto es, que protejan al acreedor de alimentos y no cuando sitúen al deudor de alimentos en una posición de ventaja (Villata \& Válková, 2020, pp. 642-643) ${ }^{40}$.

No refuerza precisamente la calificación de exclusividad el hecho de que, en materia de litispendencia del Reglamento 4/2009, siga estrictamente primando el prior tempore (art. 12 R. 4/2009), esto es, que en caso de procesos paralelos deberá conocer de la causa alimenticia el Tribunal del Estado miembro ante el que se interpuso la primera demanda, con independencia de que la competencia del segundo de ellos tenga su base en un acuerdo de elección de foro. Otra cosa sería la conveniencia de operar de manera semejante a como lo hace el art. 31.2 R. 1215 que, en evolución del Reglamento 44/2001 (antecedente, no olvidemos, del Reglamento 4/2009), modificó el prior tempore de la regla de litispendencia, para primar al segundo de los Tribunales cuando fuese el "órgano jurisdiccional de un Estado miembro que tenga competencia exclusiva en virtud de un acuerdo contemplado en el artículo 25 (sumisión expresa)". Y todo ello, con independencia de que la estrategia abusiva de las acciones torpedo resulte por el momento desconocida o inhabitual en la práctica relativa a reclamaciones de alimentos ${ }^{41}$.

En cualquier caso, que el art. 4 R. 4/2009 emplee los términos de "salvo pacto en contrario entre las partes" convierte a esta posibilidad en excepcional frente a la regla general de la exclusividad, lo que obliga a acreedor y deudor de alimentos a expresar claramente el carácter concurrente o no exclusivo del foro elegido. En consecuencia, de dudar el operador jurídico, debe atribuirse al foro elegido un carácter de exclusividad, lo que parece ser también corroborado por lo dispuesto en el art. 4.4 R. 4/2009 cuando habla de la atribución de "competencia exclusiva a un órgano jurisdiccional" del

\footnotetext{
39 También, Villata \& Válková, 2020, p. 641, en relación con el supuesto que elabora.

${ }^{40}$ Asimismo, si bien en relación con el Reglamento 1215/2012, Fernández y Sánchez, 2020, pp. 87-88. En la práctica, aunque en materias distintas de los alimentos, Sent. Cour Cass. francesa 26/9/2012 (núm. 11-26022; https://www.courdecassation.fr/jurisprudence_2/ premiere_chambre_civile_568/983_26_24187.html), respecto de la validez de la cláusula que obligaba sólo a una de las partes a demandar ante un concreto juez, empleando la otra parte foros objetivos, considerada contraria a los objetivos del art. 23 R. 44 al beneficiar únicamente a una de las partes, al igual que hizo en la Sent. Cour Cass. francesa 25/3/2015 (núm. 13-27264; https://www. legifrance.gouv.fr/juri/id/JURITEXT000030409294/). No obstante, Sent. Cour Cass. francesa 7/10/2015 (núm. 14- 16.898; https://www. courdecassation.fr/jurisprudence_2/premiere_chambre_civile_568/1053_7_32739.html), o Sent. Cour Cass. francesa 11/5/2017 (núm. 15-18758; https://juricaf.org/arret/FRANCE-COURDECASSATION-20170511-1518758), que sí las consideraron válidas. Asimismo, Sent. Corte Cass. italiana 8/3/2012 (Riv. dir. int. pr. proc., 2013, p. 142), que admitió una cláusula asimétrica (sumisión de una de las partes a los Tribunales ingleses y la otra a Tribunales italianos y foros objetivos), lo mismo que cierta práctica inglesa, como en Commerzbank Aktiengesellschaft v Liquimar Tankers Management Inc. (2017, EWHC 161 Comm). Véase, asimismo, AAP Barcelona 26/2/2009 (JUR 2009\170250; cláusula facultativa); o AAP Madrid 18/10/2013 (JUR 2013\354923; cláusulas alternativas); o Sent. BGH alemán 14/1/2014 (FamRZ, 2014, 629), sobre un acuerdo asimétrico relativo al régimen de la relación matrimonial, también los alimentos, que entiende nulo de crear un importante desequilibrio entre los cónyuges al perjudicar a la parte más débil. Sobre los tipos de cláusulas, Keyes \& Brooke, 2015, pp. 345-378.

${ }^{41}$ Abendroth, 2014, pp. 469-470, y referencia allí citada, dudando de una eventual modificación del art. 12 R. 4/2009 relativo a la litispendencia en alimentos precisamente por lo infrecuente de las acciones torpedo en esta materia.
} 
Convenio de Lugano de 2007 (Ricciardi, 2021, p. 612, nota 26; Abendroth, 2014, p. 469).

1.6.2. Consecuencias del ejercicio de la autonomía de la voluntad

No cuestionables las bondades de la introducción de la autonomía de la voluntad en materia de competencia judicial internacional en relación con las obligaciones alimenticias, es cierto que la estructura a partir de la cual el legislador europeo concibe su ejercicio en el Reglamento 4/2009 puede limitar su amplitud y no sólo por la prohibición de su juego respecto de los alimentos debidos a menores de 18 años. La exigencia de vinculación objetiva entre las circunstancias de las partes y la controversia alimenticia deja a las partes sólo la tarea de identificar el órgano jurisdiccional que más se ajusta a sus intereses dentro del abanico de foros objetivos que ya disfrutaba. Desde el momento en que los Tribunales de las respectivas residencias habituales de las partes ya tienen jurisdicción en virtud del art. 3 R. 4/2009, la elección de las partes va a suponer realmente la supresión de una de las opciones que este precepto ofrece al acreedor de alimentos, así como la posibilidad de modificación de la jurisdicción especial dentro del Estado de residencia habitual seleccionada, permitiendo además añadir un foro a favor de los Tribunales del Estado de la nacionalidad de una de las partes, ya establecido por el Reglamento 4/2009 como foro subsidiario en el art. 6 R. 4/2009 (Ancel \& Muir-Watt, 2010, p. 467; Widiez, 2019, párr. 185). Tampoco son perfectos los foros seleccionables para las reclamaciones de alimentos entre cónyuges o excónyuges. No lo son la residencia habitual o la nacionalidad de las partes desde la óptica del objetivo de acumulación de causas ante un mismo órgano jurisdiccional: su elección hace previsible para los cónyuges y excónyuges el foro de los alimentos, pero lo hace en detrimento del objetivo de la acumulación de causas ante un mismo Tribunal en tanto que el órgano jurisdiccional elegido podría no tener jurisdicción respecto del divorcio (Gandía, Faucon
\& Siaplaouras, 2020, pp. 184-185). Y tampoco la opción de los foros matrimoniales, esta vez desde la óptica de la previsibilidad. Tiene que ver con la regulación de los criterios de competencia de las crisis matrimoniales del Reglamento 2201/2003, que no facilita este objetivo, salvando el caso de seleccionar para los alimentos los Tribunales que están conociendo o que ya resolvieron de la causa matrimonial (Abendroth, 2014, p. 467). No en vano padecen de una mayor incertidumbre las partes que deciden acumular la demanda de alimentos en el proceso de divorcio en tanto que el órgano jurisdiccional para resolver la crisis matrimonial no puede decidirse de antemano debido a la imposibilidad de llevar a cabo un acuerdo de elección de foro en el Reglamento 2201/2003. Añádase a ello la habitual carrera hacia los Tribunales que provoca el forum shopping generado por el numeroso elenco de foros que el Reglamento 2201/2003 ofrece para las crisis matrimoniales, más cuando al primero en el tiempo le corresponderá conocer no sólo de la causa matrimonial, también de los alimentos (Gandía, Faucon \& Siaplaouras, 2020, pp. 184-185).

No extraña así que, desde esta óptica y con estos condicionantes vinculados al peso de los factores de conexión o la difícil coordinación con los foros matrimoniales, se haya hablado de una autonomía de la voluntad ilusoria o imperfecta en comparación con una regulación más libre basada en la única voluntad de las partes ${ }^{42}$. No obstante, su introducción en el Reglamento 4/2009 es bienvenida. Puede cuestionarse su mayor 0 menor amplitud, la valoración de una mayor flexibilidad de su juego respecto de los alimentos para menores de 18 años, así como la necesidad de una mayor coordinación con unas reglas del Reglamento 2201/2003 que no permiten la sumisión expresa o tácita a Tribunal, más cuando la autonomía de la voluntad sí se halla presente en sede de ley aplicable a la separación judicial y al divorcio. Sin embargo, y a pesar de las limitaciones al juego de la autonomía de la voluntad derivada del (necesario) peaje que supone la protección de la parte más débil de la

42 Widiez, 2019, párr. 183, que habla de "métamorphosée"; o Ancel \& Muir-Watt, 2010, p. 467, cuando hablan de "en trompe l'oeil". 
relación alimenticia, no se puede poner en duda la utilidad que, en términos de previsibilidad y disminución de los costes de litigación, tiene para las partes la posibilidad de pactar la competencia judicial internacional de aquel órgano jurisdiccional que mejor se ajuste a sus intereses materiales y económicos. Y si esto es así respecto de una cláusula básica de elección de foro determinante de la competencia única de los órganos jurisdiccionales seleccionados, más lo es respecto de aquel otro tipo de cláusulas, como las facultativas o asimétricas, cuya flexibilidad permite un mejor ajuste, aun en detrimento de la previsibilidad, con la realidad de hecho de muchas situaciones controvertidas que se generan entre acreedor y deudor de alimentos ${ }^{43}$.

\section{Obligaciones alimenticias y sumisión expresa a tribunales de terceros Estados}

2.1. Ausencia de norma reguladora en el Reglamento $4 / 2009$

Dentro del libre ejercicio de su autonomía de la voluntad, nada impide que las partes decidan someter sus eventuales controversias relativas a las obligaciones de alimentos a los Tribunales de un tercer Estado (Chile, Estados Unidos, Argentina...). La normativa reguladora de la competencia judicial internacional del Reglamento 4/2009 no responde a esta situación: el art. 4 R. 4/2009 sólo habla de elección de un "órgano u órganos jurisdiccionales (...) de un Estado miembro”.

Si la intención del legislador europeo con el Reglamento 4/2009 era procurar un régimen competencial de alcance universal, como lo muestra, a diferencia de su antecedente, el juego en todo caso de las reglas de competencia de este instrumento ( $y$ no de las reglas domésticas) con independencia de la domiciliación comunitaria del demandado ${ }^{44}$, llama la atención la ausencia de previsión respecto de una eventual elección de foro a favor de Tribunales de terceros Estados (Kohler,
2008 , p. 1178$)^{45}$. No cuenta como tal el caso de la eventual elección de los Tribunales de un Estado de la EFTA no comunitario, que sí regula el legislador europeo y que veremos, en tanto que no son propiamente terceros Estados dada la vinculación de la UE con Suiza, Islandia y Noruega a partir del Convenio de Lugano de 2007.

Desde la óptica de un Tribunal de un Estado miembro, no parece que la no regulación de la elección de los órganos jurisdiccionales de un tercer Estado suponga la inoperatividad en todo caso de una cláusula semejante y, con ello, la competencia de este Tribunal con base a los foros objetivos del Reglamento 4/2009, de ser el caso (Kohler, 2008, p. 1178; Deschamps, 2011, p. 808). La mejor opción pasaría, en orden a ese espíritu de universalidad del Reglamento 4/2009, por la elaboración por parte del legislador europeo de un foro de competencia que, sujeto a ciertos límites y condiciones, contemplase la situación de elección de un Tribunal de un tercer Estado (Kohler, 2008, p. 1179), siguiendo así la línea de distintas propuestas doctrinales relativas a instrumentos semejantes perfectamente trasladables al Reglamento

\footnotetext{
${ }^{43}$ Véase el ejemplo puesto por Villata \& Válková, 2020, p. 641.

${ }^{44}$ Fernández y Sánchez, 2020, p. 543, sobre este alcance universal y el no juego de las reglas españolas de competencia judicial internacional del art. 22 LOPJ relativas a las obligaciones de alimentos.

${ }^{45}$ Respecto de la interacción con terceros Estados desde la óptica del Reglamento 4/2009, en relación con instituciones como la litispendencia, véase Beaumont, 2020, párr. II.
} 
de alimentos ${ }^{46}$. Nada aparece en el Reglamento 4/2009, como tampoco en lo que es el Reglamento 1215/2012 en su papel de instrumento que reformó un Reglamento 44/2001 que, como es sabido, conforma el antecedente del Reglamento de alimentos.

2.2. Alternativas de respuesta: del efecto reflejo del art. 4 R. 4/2009 hasta la aplicación del Derecho doméstico

En esta coyuntura, una posibilidad pasaría por considerar una suerte de efecto reflejo del art. 4 R. 4/2009, en una aplicación por analogía del foro europeo regulador de la elección de foro en materia de obligaciones alimenticias, teniendo en cuenta sus principios y convenientemente adaptado a la participación de un tercer Estado ${ }^{47}$. Las dificultades que esta alternativa pueda acarrear a un operador jurídico de un Estado miembro que opera en ausencia de norma comunitaria reguladora del caso, así como el riesgo al objetivo de interpretación uniforme del Reglamento 4/2009, parecen dejar poco recorrido a esta posibilidad.

Una alternativa final podría ser, en fin, el recurso al Derecho nacional ${ }^{48}$, que es lo que también se propugna respecto de esta misma ausencia de norma en el Reglamento 1215/201249. Supondría, en este caso, la aplicación de las reglas domésticas relativas a la derogatio fori, que, desde la óptica del Derecho español, conducirían a la exclusión de la competencia del Tribunal español respecto de la demanda de alimentos en tanto que tal competencia "podrá ser excluida mediante un acuerdo de elección de foro a favor de un Tribunal extranjero" (art. 22ter.4 LOPJ). No obstante, recurrir al Derecho doméstico casa mal con el objetivo del legislador europeo de conseguir una reglamentación exhaustiva y, sobre todo, una interpretación uniforme del Reglamento 4/2009 en materia de alimentos (Kohler, 2008, p. 1178; Deschamps, 2011, p. 808). Más todavía cuando no existe garantía alguna de que los Derechos procesales nacionales de los Estados miembros contemplen en sus legislaciones reglamentaciones relativas a la derogatio fori. Es lo que sucedía en el Derecho español antes de la reforma operada por la Ley Orgánica 7/2015, de 21 de julio, por la que se modifica la Ley Orgánica 6/1985, de 1 de julio, del Poder Judiciapº, cuya versión de 1985 no trataba la cuestión y, con ello, el riesgo a la seguridad jurídica que la ausencia de norma generaba en el operador jurídico enfrentado a esta situación ${ }^{51}$. Y, aun existiendo, su tratamiento puede no ser completo, como sucede asimismo en el Derecho español cuando, después de establecer la suspensión del procedimiento en España y de permitir su continuación únicamente en el supuesto de que los Tribunales extranjeros hubiesen declinado su competencia, no fija un plazo para que el interesado plantee su reclamación ante el Tribunal extranjero designado, con lo que la suspensión puede ser sine die ${ }^{52}$. A lo expuesto, añádase la inoperatividad de la derogatio fori en aquellas materias en las que en

\footnotetext{
${ }^{46}$ Esta problemática de no regulación de la elección de Tribunales de terceros Estados ya la puso de manifiesto, si bien con carácter general, cuando las obligaciones alimenticias todavía formaban parte del ámbito material del Reglamento 44/2001, el Grupo Europeo de Derecho internacional privado (XIXª reunión, septiembre 2008, Bergen); al respecto, https://gedip-egpil.eu/wp-content/uploads/2008/10/ GEDIP-18e-session-Commentaire.pdf. O Study on Residual Jurisdiction (Review of the Member State's Rules concerning "Residual Jurisdiction" of their courts in Civil and Commercial Matters pursuant to the Brussels I and II Regulations", Nuyts, A. (dir.), JLS/C4/2005/07, 2007. Recuperado de: https://citeseerx.ist.psu.edu/viewdoc/download?doi=10.1.1.193.8681\&rep=rep1\&type=pdf [fecha de consulta: 26 de octubre de 2021].

${ }^{47}$ La contempla como posibilidad, Kohler, 2008, p. 1178; o Abendroth, 2014, p. 469 y referencias allí citadas, que consideran la evaluación de un pacto a favor de un Tribunal de un tercer Estado ex art. 4 R. 4/2009 cuando, de no ser por este acuerdo de elección, un Tribunal de un Estado miembro hubiera tenido competencia.

${ }^{48}$ La contempla como posibilidad, Kohler, 2008, p. 1178.

49 En relación con este otro instrumento, Fernández y Sánchez, 2020, p. 87.

50 BOE 22/7/2015.

${ }^{51}$ Sobre la situación anterior a la reforma de la LOPJ, cuya ausencia de norma regulando la derogatio fori suponía su admisión en ocasiones (considerando la cláusula de elección del Tribunal del tercer Estado y la no competencia de los Tribunales españoles) y lo contrario en otras (ignorando la cláusula y declarando la competencia objetiva del Tribunal español), Fernández y Sánchez, 2020, pp. 124125, o, más desarrollado, en cualquiera de las versiones de esta obra anteriores a 2015.

52 Sobre ello, Garcimartín, 2015, párr. V.
} 
el Derecho español no cabe la prorrogatio fori. Porque, estando claro que las obligaciones alimenticias son materia disponible desde la óptica del Reglamento 4/2009, no lo es tanto que también lo sean desde el punto de vista del D.i.pr. español de fuente doméstica ${ }^{53}$. Recuérdese que art. 22 bis.1 LOPJ sólo admite el juego de la autonomía de la voluntad "en aquellas materias en que una norma expresamente lo permita", de manera que "no tendrá efecto la exclusión de la competencia de los Tribunales españoles en aquellas materias en que no cabe sumisión a ellos" (art. 22ter.5 LOPJ). Y parece claro su permiso en materias como las obligaciones contractuales y extracontractuales o derechos reales sobre bienes muebles del art. 22 quinquies LOPJ: si este precepto admite el ejercicio de la autonomía de la voluntad con limitaciones en relación con los contratos de consumo y seguros, jugaría a sensu contrario sin limitaciones en el resto de las materias, más, cuando este art. 22 quinquies LOPJ se encarga de establecer aquellos foros objetivos operativos "en defecto de sumisión expresa o tácita". No sucede así con las obligaciones alimenticias: no son materia del art. 22 quinquies LOPJ, sino del art. 22 quater f) LOPJ, que establece los foros objetivos en materia de Derecho de familia, presidido por el principio inquisitivo y operativo "en defecto de criterios anteriores", entre los que no se halla la sumisión expresa o tácita. Si bien difícilmente justificable, las obligaciones alimenticias no son materia objeto de la autonomía de la voluntad desde la óptica del D.i.pr. español autónomo ${ }^{54}$.

Visto lo visto, y aun cuando se esté recurriendo al Derecho nacional, convendría, pues, la existencia de una norma ad hoc en el Reglamento 4/2009, que no se prevé, que guíe al operador jurídico de un Estado miembro a la hora de enfrentarse a una demanda de alimentos existente una cláusula de elección de foro respecto de Tribunales de terceros Estados.

\section{Sumisión Expresa: posible aplicación del Convenio de Lugano de 2007 a la Reclamación de Alimentos}

3.1. Los arts. 64 CL 2007 y el art. 4.4 R. 4/2009: cláusulas de compatibilidad

Dentro del libre ejercicio de su autonomía de la voluntad, y al igual que antes, nada impide que las partes decidan someter sus eventuales controversias relativas a las obligaciones de alimentos a los Tribunales de un Estado de la EFTA no comunitario. A diferencia de lo que sucedía respecto de las cláusulas de elección de foro a favor de Tribunales de terceros Estados, el legislador europeo sí hace referencia a esta posibilidad cuando establece que, "si las partes hubieren acordado atribuir una competencia exclusiva a un órgano jurisdiccional o a los órganos jurisdiccionales de un Estado parte en el Convenio (de Lugano) y dicho Estado no fuere un Estado miembro, dicho Convenio será de aplicación" (art. 4.4 R. 4/2009). Esta respuesta debe integrarse con lo dispuesto en el Convenio de Lugano de 2007 como régimen que, al igual que el Reglamento 4/2009, regula la competencia judicial internacional en materia de alimentos y que también establece la aplicación preferente de la normativa convencional, esta vez cuando "(el artículo)

\footnotetext{
${ }^{53}$ Señala las dificultades para definir el alcance del ejercicio de la autonomía de la voluntad en la LOPJ dada su defectuosa redacción, Garcimartín, 2015, párr. V.

54 Sobre esta polémica, Fernández y Sánchez, 2020, pp. 115-116.
} 
23 del presente Convenio otorgare(n) competencia a los Tribunales" de un Estado de la EFTA no comunitario (art. 64.2.a CL 2007).

En efecto, a la hora de determinar su competencia judicial internacional en materia de obligaciones alimenticias, los órganos jurisdiccionales pertenecientes a un Estado miembro de la UE se hallan vinculados tanto por el Reglamento 4/2009 como por el Convenio de Lugano de 2007. No en vano este Convenio regula la competencia judicial internacional y el reconocimiento y/o ejecución de resoluciones extranjeras en materia civil y mercantil, incluyendo dentro de su ámbito a las obligaciones alimenticias, extendiendo las soluciones del Convenio de Bruselas de 1968 (y de sus modificaciones posteriores en forma del Reglamento 44/2001) a los Estados parte de la Asociación Europea de Libre Comercio (AELC - EFTA), en concreto, a Suiza, Islandia y Noruega ${ }^{55}$.

Esta doble vinculación del operador jurídico de un Estado miembro respecto de una demanda relativa a obligaciones alimenticias exige la identificación del régimen preferencial conforme al cual debe valorar finalmente su competencia judicial internacional, lo que pasa por la consulta de aquellas cláusulas de compatibilidad encargadas de regular la convivencia entre el Reglamento 4/2009 y el Convenio de Lugano de 2007. A nuestro entender, y a pesar de la existencia del art. 4.4 R. 4/2009, esta cláusula sigue siendo el art. 64 CL 2007 (anterior art. 54 ter CL 1988), que era la norma que regulaba esta convivencia cuando los alimentos formaban parte del Reglamento 44/2001: si el legislador europeo no estableció de manera expresa regla distinta alguna en el Reglamento 4/2009, permaneciendo además inalterable el art. 64 CL 2007 a pesar del cambio de sede de las obligaciones alimenticias en el espacio judicial europeo, no existe razón alguna para pensar en su no aplicación mientras siga siendo materia regulada por el Convenio de Lugano de 2007. O, lo que es lo mismo, la posterior exclusión de los alimentos del ámbito de aplicación del Reglamento 1215/2012 para situarlos en el Reglamento 4/2009 no cambia la situación ${ }^{56}$, más todavía cuando este cambio de sede no supuso ningún tipo de modificación en el tenor del art. $64 \mathrm{CL}$ 2007 buscando su adaptación a la nueva situación en tanto que el Convenio de Lugano de 2007 seguía (sigue) regulando los alimentos.

No altera el panorama la presencia en el Reglamento 4/2009 de un art. 4.4 R. 4/2009 que, como vimos, se pronuncia en términos semejantes al art. 64.2.a CL 2007. Tiene poco sentido entender que el legislador europeo esté utilizando el criterio del art. 4.4 R. 4/2009 como regla única directora del juego de compatibilidades entre el Convenio de Lugano y el Reglamento 4/2009, en este caso, limitando aquellas situaciones en las que resultan operativas en materia de obligaciones alimenticias las disposiciones del Convenio de Lugano de 2007. De ser así, la aplicación del Convenio de Lugano de 2007 se produciría sólo en aquellos casos en los que acreedor y deudor de alimentos hubiesen acordado conceder competencia judicial a Tribunales de Islandia, Noruega o Suiza, lo que implicaría la aplicación del Reglamento 4/2009 en el resto de supuestos aunque se tratase de situaciones vinculadas a los Estados de la EFTA, esto es, en un sentido opuesto a lo indicado en un art. 64.2 CL 2007 que llevaría, por el contrario, a la aplicación preferente del Convenio de Lugano ${ }^{57}$. Esta supuesta aplicación preferente del Convenio de Lugano de 2007

\footnotetext{
${ }^{55}$ El Convenio de Lugano de 1988, que extendió las soluciones del Convenio de Bruselas de 1968, incluido el foro de competencia sobre alimentos, vinculaba a los Estados parte de la EFTA y a los Estados de la UE. Tras 1988, varios Estados parte en el Convenio de Lugano se adhirieron a la Comunidad Europea (CE) y pasaron a ser parte del Convenio de Bruselas (Finlandia, Suecia y Austria, miembros de la CE el 1/1/1995, siendo ya partes en el Convenio de Lugano desde el 1/4/1993). Fue sustituido por el Convenio de Lugano de 2007, celebrado entre la CE, Dinamarca (tras la firma del Convenio en Bruselas el 5/12/2007), Islandia, Noruega y Suiza, buscando su adaptación al Reglamento 44/2001.

${ }^{56}$ Parten de la aplicación del art. 64 CL 2007, expresamente o de manera implícita, por ejemplo, Ancel \& Muir Watt, 2010, p. 468; o Fernández y Sánchez, 2020, p. 541 y p. 543.

57 Sobre ello, Rueda, 2013, p. 610.
} 
limitada sólo a los casos del art. 4.4 R. 4/2009, ignorando la existencia y exigencias del art. $64 \mathrm{CL} 2007$, regulador también de los alimentos y régimen vinculante también para los Estados miembros, no encajaría con el respeto a los compromisos internacionales asumidos por los Estados miembros de la UE a través del art. 64 CL 2007.

Es cierto que este art. 4.4 R. 4/2009 tiene el mismo efecto que una cláusula de compatibilidad, esto es, la determinación del régimen que un Tribunal de la UE va a aplicar a la hora de valorar su competencia judicial internacional en materia de alimentos. Sin embargo, este precepto se halla situado en el capítulo II del Reglamento 4/2009 dedicado a la competencia judicial internacional y lo que hace es elaborar una regla especial contenida en la regla de competencia del art. 4.4 R. 4/2009 con la intención, como veremos, de establecer una excepción a la aplicación preferente del Convenio de Lugano de 2007 respecto de "los litigios relativos a la obligación de alimentos respecto de un menor de edad inferior a 18 años" (art. 4.3 R. 4/2009). La intención del legislador europeo no es, pues, sustituir la cláusula de compatibilidad del art. 64 CL 2007, sino emplear este art. 4.4 R. 4/2009 para excepcionar en ciertos casos la aplicación de la regla implícita del art. 64.2.a CL $2007^{58}$.

3.2. Demanda de alimentos ante un Tribunal comunitario y sumisión expresa a favor de un Tribunal de un Estado de la EFTA

Visto lo visto, piénsese en aquella situación de demanda de alimentos incoada ante los órganos jurisdiccionales de un Estado miembro, existiendo una cláusula de sumisión expresa entre acreedor y deudor de alimentos a favor de un Tribunal de un Estado de la EFTA no comunitario. De acuerdo con lo expuesto, y siguiendo el tenor del art.
64 CL 2007, que mantendría su operatividad a modo de cláusula de compatibilidad implícita, la aplicación preferente del Convenio de Lugano de 2007 por parte de los órganos jurisdiccionales de un Estado miembro enfrentados a una demanda relativa a obligaciones de alimentos se produciría cuando el art. 23 CL 2007, regulador de las cláusulas atributivas de jurisdicción por sumisión expresa, conceda competencia única a un Tribunal de un Estado de la EFTA, en concreto, a los órganos jurisdiccionales suizos, noruegos o islandeses ${ }^{59}$. Así lo entiende el art. 64.2.a CL 2007, de mismo modo que dispone el art. 4.4 R. 4/2009 (Fernández y Sánchez, 2020, p. 543; o Álvarez, 2009, párr. II.4 y párr. V.2).

Dado que el art. 23 CL 2007 concede competencia exclusiva a los Tribunales seleccionados por acreedor y deudor de alimentos ("esta competencia será exclusiva, salvo pacto en contrario entre las partes"), el Tribunal del Estado miembro donde se interpuso la demanda deberá declinar su competencia, con independencia de que ésta pueda venirle atribuida por un foro objetivo del Convenio de Lugano de 2007, esto es, por el domicilio del demandado del art. 2 CL 2007, o bien, además de por los foros por accesoriedad relativos a las crisis matrimoniales o responsabilidad parental, por el lugar del domicilio o de la residencia habitual del acreedor de alimentos del foro especial del art. 5.2 CL 2007 (Dickinson \& Lein, 2015, p. 583). La inaplicación del Reglamento 4/2009 para este tipo de situaciones convierte en irrelevante una eventual competencia del Tribunal comunitario por cualquiera de los foros objetivos de este instrumento.

Ahora bien, la aplicabilidad del art. 23 CL2007 por parte del órgano jurisdiccional comunitario pasa por el hecho de la domiciliación de "al menos una de (las partes) (...) en un Estado vinculado por el presente Convenio" (art.

\footnotetext{
${ }^{58}$ Véase, por ejemplo, Fernández y Sánchez, 2020, p. 543, utilizando el art. 4.4 R. 4/2009 en caso de sumisión expresa y el art. 64 CL 2007 para el resto de las situaciones.

${ }^{59}$ En la práctica, si bien en una materia distinta de los alimentos, STJUE 15/11/2012, As. C-456/11, Gothaer, cuando alude a una cláusula atributiva de jurisdicción a favor de los Tribunales islandeses en un caso de reconocimiento relativo a una relación contractual de transporte.
} 
23.1 CL 2007), a diferencia de lo dispuesto en el art. 4 R. $4 / 2009$, operativo con independencia del domicilio de las partes. De hallarse las partes domiciliadas en un tercer Estado, la elección de un Tribunal de un Estado de la EFTA exige del Tribunal de la UE valorar la eficacia del acuerdo atributivo de jurisdicción, no por el régimen del Convenio de Lugano ni por el propio del Reglamento 4/2009, sino por las reglas de su Derecho nacional (Dickinson \& Lein, 2015, p. 583) ${ }^{60}$. Aunque no es ésta última una situación propia del Convenio de Lugano de 2007 sino del Derecho doméstico de cada Estado, el peso de la autonomía de la voluntad justifica la intervención del legislador de Lugano imponiendo una cautela al comportamiento de los Tribunales no elegidos, al disponer que, "cuando ninguna de las partes que hubieren celebrado un acuerdo de este tipo estuviere domiciliada en un Estado vinculado por el presente Convenio, los Tribunales de los demás Estados vinculados por el presente Convenio solo podrán conocer del litigio cuando el Tribunal o los Tribunales designados hubieren declinado su competencia" (art. 23.3 CL 2007). Finalmente, el convenio atributivo de competencia del art. 23 CL 2007 deberá ajustarse a las exigencias formales del art. 23 CL 2007, equivalentes a las propias del art. 23 R. 44 y alejadas de las más restrictivas del art. 4 R. 4/2009.

3.3. Demanda de alimentos ante un Tribunal comunitario y sumisión expresa a favor de un Tribunal de un Estado de la EFTA: la excepción relativa a alimentos a menores

Piénsese ahora en la misma situación anterior de demanda de alimentos incoada ante los órganos jurisdiccionales de un Estado miembro, existiendo esta vez una cláusula de sumisión expresa entre padre y madre relativa a los alimentos de un menor y, como antes, a favor de un Tribunal de un Estado de la EFTA. La prevalencia del Convenio de Lugano de 2007 con base en la existencia de una cláusula de sumisión expresa a favor de los Tribunales de la EFTA (art. 64.2.a CL 2007 y art. 4.4 R. 4/2009), propia de la situación anterior, se quiebra en este nuevo caso por la presencia de un menor: el art. 4.4 R. 4/2009 recoge una excepción a esta aplicación preferente cuando estima que este "Convenio será de aplicación excepto en lo referente a los litigios mencionados en el apartado 3", que son los "litigios relativos a la obligación de alimentos respecto de un menor de edad inferior a 18 años" (art. 4.3 R. 4/2009).

\section{Ello supone lo siguiente.}

Primero. El Tribunal del Estado miembro donde se interpuso la demanda de alimentos del menor debe valorar la competencia a partir del Reglamento 4/2009 y no del Convenio de Lugano de 2007 (Álvarez, 2009, párr. II.4; Ancel \& Muir Watt, 2010, pp. 466-468). En consecuencia, este Tribunal puede declararse competente por cualquiera de los foros objetivos que el Reglamento 4/2009 le proporciona; por ejemplo, con base en la residencia habitual del menor en ese Estado miembro del art. 3 R. 4/2009. O, lo que es lo mismo, no deroga su competencia una eventual impugnación con base en la existencia de este acuerdo atributivo de jurisdicción aun cuando tal pacto resulta perfectamente válido de acuerdo con las disposiciones del Convenio de Lugano de 2007. Segundo. Aun cuando no es alegable ante los Tribunales de un Estado miembro, el acuerdo de sumisión expresa sí sería operativo ante un Tribunal de un Estado de la EFTA vinculado por el Convenio de Lugano a fin de determinar su competencia (Álvarez, 2009, párr. II.4 y párr. V.2; Despina \& Rodriguez, 2009, p. 584). Una eventual demanda ante los Tribunales del Estado de la EFTA seleccionados por el acuerdo de voluntades supondría su competencia en atención al art. 23 CL 2007, plenamente operativo desde su óptica como órgano jurisdiccional no vinculado por el Reglamento 4/2009 y, por tanto, ajeno a lo dispuesto en el art. 4.4 R. 4/2009. Tercero. La existencia de un

60 También, Gaudemet-Tallon, 2015, p. 632, nota 23, si bien aludiendo a estas cláusulas del art. 17.1 in fine CL 1988 (actual art. 23.3 CL 2007). 
pacto a favor de los Tribunales de un Estado de la EFTA, determinante a priori de la competencia exclusiva de los órganos jurisdiccionales seleccionados por la autonomía de la voluntad, no impedirá la concurrencia competencial de los Tribunales de un Estado miembro a partir de los foros objetivos del Reglamento 4/2009 (Kostkiewicz \& Eichenberger, 2015, p. 25).

No nos parece de recibo este distinto alcance para un mismo acuerdo atributivo de jurisdicción, y menos cuando su efecto era el mismo bajo el régimen anterior del Reglamento 44/2001 y Convenio de Lugano de $2007^{61}$. No sólo por la distinta operatividad de la cláusula en función del lugar donde se interpone la demanda, siendo como son todos Tribunales de Estados parte del Convenio de Lugano de 2007, también porque este distinto alcance se produce a partir de la sola intervención del legislador europeo, que modifica unilateralmente el alcance del art. 23 CL 2007 sin tener competencia para ello y sin contar con el legislador de los Estados parte de la EFTA, esto es, al determinar unilateralmente por medio del Derecho de la UE el alcance de sus compromisos internacionales con terceros Estados (Rueda, 2013, p. 610; Álvarez, 2009, párr. II.4).

3.4. Demanda de alimentos ante un Tribunal comunitario: sumisión expresa a favor de un Tribunal de un Estado miembro

3.4.1. Sumisión expresa a favor de un Tribunal de un Estado miembro y domicilio del demandado de alimentos en un Estado de la EFTA

Ausentes menores, piénsese en aquella otra situación de existencia de una cláusula de elección de foro entre acreedor y deudor de alimentos a favor de los órganos jurisdiccionales de un Estado de la UE. La irrelevancia de la ubicación del domicilio de las partes en orden a la operatividad del art. 4 R. 4/2009 regulador de la sumisión expresa en el Reglamento 4/2009 no parece cuestionar la aplicabilidad de este instrumento por parte de los Tribunales comunitarios ante los que se plantea la demanda, sean los elegidos, para declararse competentes, sean cualesquiera otros Tribunales comunitarios, esta vez para abstenerse de conocer.

La ubicación del domicilio del demandado en un Estado parte de la EFTA introduce, no obstante, una variante que puede conducir a la aplicación del Convenio de Lugano de 2007 por parte del Tribunal comunitario: no en vano el art. 64.2.a CL 2007 establece que "el presente Convenio se aplicará, en cualquier caso: (...) en materia de competencia (...) cuando el demandado estuviere domiciliado en un Estado" de la EFTA. No es cuestión menor. La aplicabilidad del art. 23 CL 2007, que parte de la domiciliación de que al menos una de las partes en un Estado parte del Convenio, permite seleccionar cualquiera de los Tribunales de la UE, mientras que el art. 4 R. 4/2009, como vimos, permite a acreedor y deudor seleccionar sólo unos determinados Tribunales.

A nuestro juicio, debe aplicarse con carácter preferencial el Reglamento 4/2009. Por un lado, los criterios que maneja el art. 64 CL 2007 no tienen carácter alternativo, de modo que no debería apelarse al domicilio del demandado a la hora de justificar esta prevalencia cuando, al igual que sucede con las competencias exclusivas, está en juego un acuerdo atributivo de jurisdicción ${ }^{62}$. Por otro, porque, de apelar al criterio

\footnotetext{
${ }^{61}$ Sobre este polémico distinto alcance, entre otros, Pocar \& Viarengo, 2009, pp. 814-815; o Rodríguez, 2011 , p. 225.

62 Aunque sobre el Reglamento 1215/2012, Fernández y Sánchez, 2020, p. 76, cuando sostienen la aplicación del art. 25 R. 1215 (y no del equivalente en el Convenio de Lugano de 2007), al entender que, si los Tribunales seleccionados son parte de la UE, un Tribunal de un Estado UE no procedería a aplicar el Convenio de Lugano de 2007 por la domiciliación del demandado en un Estado de la EFTA; asimismo, expone esta posibilidad, si bien sin decantarse por ella, Dickinson \& Lein, 2015, p. 583. En contra, Domej, 2011, pp. 944-945, cuando parece considerar, en relación con este tipo de situaciones, la aplicación preferente del Convenio de Lugano de 2007 atendiendo a la domiciliación del demandado en un Estado de la EFTA.
} 
del domicilio del demandado en un Estado de la EFTA para justificar la prevalencia del Convenio de Lugano de 2007, un mismo pacto firmado por acreedor y deudor de alimentos sería valorado por dos regímenes diferentes y, con ello, susceptible de recibir distintos alcances: el régimen aplicable sería decidido por la posición procesal que ocupe cada parte en el proceso, poco ajustado al principio de tutela judicial efectiva al poner en riesgo la igualdad entre las partes. Y, finalmente, porque la valoración del pacto con base a las exigencias del Reglamento 4/2009 se ajusta mejor al objetivo de protección de la posición de debilidad del acreedor de alimentos, basada en el respeto a los límites que impone este instrumento relativos a los Tribunales a elegir, frente a la mayor libertad del art. 23 CL 2007.

3.4.2. Sumisión expresa a favor de un Tribunal de un Estado miembro y la excepción relativa a alimentos a menores: conflicto negativo de jurisdicciones en relación con el Convenio de Lugano de 2007

Piénsese en un acuerdo de voluntades entre padre y madre de un menor de 18 años residente en un Estado de la EFTA a favor de los Tribunales de un Estado miembro. De acuerdo con lo expuesto, los Tribunales comunitarios no serían competentes por la inoperatividad de la cláusula al tratarse de menores de 18 años (art. 4.4 R. 4/2009), por ubicarse la residencia habitual del menor en un Estado de la EFTA, y, tampoco, de ubicarse la residencia habitual del demandado (el padre deudor, por ejemplo) en un tercer Estado, no coincidiendo en ningún Estado miembro la nacionalidad común de acreedor y deudor de alimentos (art. 6 R. 4/2009). La alternativa de la madre reclamante sería presentar la demanda en el Estado de la EFTA de residencia habitual del menor, apelando al foro especial del art. 5.2 CL 2007 del lugar de la residencia habitual y/o domicilio del acreedor de alimentos. Sin embargo, la competencia de los Tribunales de este Estado de la EFTA tampoco sería posible en tanto que, a diferencia de lo que sucede con el art. 4.4. R. 4/2009, la cláusula de sumisión a favor del Tribunal de la UE sí sería válida según el art. 23 CL 2007, convirtiendo ex derogatio fori en exclusivamente competentes a los Tribunales comunitarios elegidos en detrimento de los foros objetivos.

No es imposible, por tanto, un conflicto negativo de jurisdicciones ${ }^{63}$, lo que obligaría al Tribunal comunitario a apelar, de darse las condiciones, al forum necessitatis del art. 7 R. 4/2009; por ejemplo, de coincidir la nacionalidad de una de las partes con el Estado al que pertenece el Tribunal comunitario ante el que se presenta la reclamación de alimentos (Considerando núm. $16 \mathrm{R}$. 4/2009) o por la presencia de bienes del demandado en el territorio de este Estado miembro ${ }^{64}$.

La lectura de este conflicto negativo de jurisdicciones no es tanto como solucionarlo, sino lo que representa: la necesidad de adoptar una regla propia de compatibilidad ajustada a las restricciones al ejercicio limitado de la autonomía de la voluntad que, en materia de los alimentos, proporciona el Reglamento 4/2009, bien creando una nueva regla de compatibilidad entre ambos instrumentos, bien adaptando el art. 23 CL 2007 al juego restrictivo de los pactos relativos a menores de 18 años propio del art. 4.4 R. 4/2009 (Despina \& Rodriguez, 2009, p. 584 y nota 21$)$.

\footnotetext{
${ }^{63}$ Véanse Kostkiewicz \& Eichenberger, 2015, pp. 25-26, cuando plantean, aunque desde la óptica del ordenamiento jurídico suizo, este eventual conflicto negativo de jurisdicciones.

${ }^{64}$ Sobre este foro de necesidad, Álvarez, 2009, párr. V.4.
} 


\section{Sumisión tácita y obligaciones alimenticias}

4.1. Demanda de alimentos: comparecencia y no impugnación

Además de la sumisión expresa y a pesar de la ambigüedad de un art. 5 R. 4/2009 cuyo título habla sólo de "competencia basada en la comparecencia del demandado"65, el Reglamento 4/2009 recoge asimismo la posibilidad de ejercicio de la autonomía de la voluntad en materia de obligaciones alimenticias a través del foro de la sumisión tácita cuando establece la competencia del "órgano jurisdiccional del Estado miembro ante el que compareciere el demandado" (art. 5 R. 4/2009) ${ }^{66}$. Fundamentada en el comportamiento procesal de acreedor y deudor de alimentos, y sin particularidad especial por su proyección en el ámbito específico de las obligaciones alimenticias ${ }^{67}$, supone la presentación de una demanda de alimentos por parte de acreedor o deudor ante un órgano jurisdiccional de un Estado miembro, seguida de la comparecencia del demandado realizando cualquier comportamiento procesal que no sea aquél de la impugnación de la competencia. Tal como establece el art. 5 R. 4/2009, "esta regla no será de aplicación si la comparecencia tuviere por objeto impugnar la competencia".

Aunque no vamos a entrar en aspectos de carácter general, no existe duda respecto de la proyección de la jurisprudencia del TJUE, aunque generada principalmente con base en la sumisión tácita del Reglamento 1215/2012 (o anteriores Reglamento 44/2001 y Convenio de Bruselas de 1968), sobre las condiciones de operatividad del art. 5 R. 4/2009 (Pocar, 2009, p. 11). Recuérdese únicamente que no se producirá sumisión tácita en aquellos casos en los que el demandado impugna no sólo la competencia sino también el fondo del litigio ${ }^{68}$, a condición de que la impugnación de la competencia, si no es previa a cualquier defensa en cuanto al fondo, no se realice con posterioridad al momento de la toma de posición considerada por el Derecho procesal interno como la primera defensa dirigida al juez competente ${ }^{69}$. Por tanto, no se produciría sumisión tácita aun cuando el deudor de alimentos haya contestado sobre el fondo,

\footnotetext{
${ }^{65}$ En relación con la oscuridad de los términos empleados muchas veces por el legislador europeo, entre los que incluye este art. 5 R. 4/2009, Garau, 2011, p. 134, nota 12.

${ }^{66}$ Véase, por ejemplo, STS 17/2/2021 (RJ 2021\460), en relación con un proceso de divorcio de dos ciudadanos franceses residentes en España en el momento de la demanda, cuando habla de aplicabilidad de las reglas del art. 3 R. 4/2009 "en defecto de sumisión expresa o tácita" (FD III.4); o SAP Cantabria 8/10/2013 (JUR 2013\350297), respecto de una demanda de modificación de la obligación de alimentos impuesta al demandante, residente en Santander, en favor del hijo común, menor de edad, residentes la demandada y el hijo común en la República Checa: verificada su incompetencia por los foros objetivos del art. 3 R. 4/2009, la competencia, tal como señala el Tribunal, sólo podía derivarse de la autonomía de la voluntad, no obstante tampoco operativa ("en el caso presente no resultan de aplicación los fueros voluntarios"; FD 2). También, STJUE 20/9/2018, As. C-214/17, Mölk, sobre un padre residente en Austria que presenta una acción de revisión de una resolución de alimentos dictada por los Tribunales austríacos ante la jurisdicción de este país. El acreedor, residente habitual en Italia, había contestado al fondo de la demanda, sin impugnar la competencia de estos Tribunales, competentes ex art. 5 R. 4/2009. O Sent. Cour d'Appel Douai 16/5/2016 (núm. 15/04009), sobre una demanda de divorcio de dos cónyuges franceses, en la que, además de para el divorcio (art. 3 R. 2201), los Tribunales franceses se declararon competentes respecto de la pensión alimenticia reclamada por la esposa y la hija contra el padre y esposo por sumisión tácita, si bien con base en el art. 24 R. 44, por su comparecencia y no impugnación.

${ }^{67}$ Véase Corrao, 2011, p. 129, señalando su semejanza con el régimen del anterior art. 24 R. 44, en oposición a su alejamiento del art. 23 R. 44 en lo que a sumisión expresa se refiere.

${ }^{68}$ Véase STJCE 24/6/1981, As. C-150/80, Elefanten Schuh GmbH; STJCE 22/10/1981, As. C-27/81, Rohr/Ossberger; STJCE 31/3/1982, As. C-25/81, C.H.W/G.J.H; o STJUE 13/6/2017, As. 433/16, Bayerische Motoren Werke.

69 Véase STJCE 24/6/1981, As. C-150/80, Elefanten Schuh GmbH.
} 
siempre que lo haya hecho a título subsidiario respecto de su intención primera de comparecer para impugnar la competencia. O, en sentido inverso, sería posible considerar la existencia de sumisión tácita en aquellos casos en los que el deudor de alimentos impugne la competencia a título subsidiario respecto de su intención primera de contestar sobre el fondo. Con todo, la flexibilidad de esta jurisprudencia a la hora de enfrentarse a la sumisión tácita no cabe en ordenamientos como el español: el hecho de que la legislación procesal española exija la interposición de un incidente de previo pronunciamiento (la declinatoria internacional: arts. 39 y 63 a 65 LEC) en orden a impugnar la competencia, obliga a considerar cualquier acto posterior del demandado como una sumisión tácita, incluso si contesta a la demanda impugnando en primer lugar la competencia (Fernández y Sánchez, 2020, p. 91) ${ }^{70}$. Siguiendo la línea habitual del legislador europeo, téngase en cuenta que el cauce procesal oportuno para impugnar la competencia no viene determinado por ninguna regla uniforme del
Reglamento 4/2009, sino por el Derecho procesal interno de cada Estado.

A diferencia del carácter exclusivo de la sumisión expresa, no parece cuestionable el carácter concurrente y alternativo del foro de la sumisión tácita (Ricciardi, 2021, p. 612), pronunciándose el art. 5 R. 4/2009 respecto de su operatividad "(c)on independencia de los casos en los que su competencia resultare de otras disposiciones del presente Reglamento"71. Desde esta óptica, y aunque la sumisión tácita tiene su verdadero sentido en supuestos donde el órgano jurisdiccional ante el que se interpone la demanda de alimentos no es competente, no es relevante que el Tribunal ante el que se interpone la demanda y se comparece sea o no objetivamente competente (Bambust, 2009, p. 384) ${ }^{72}$. Tampoco que haya habido o no una previa voluntad expresa ex art. 4 R. 4/2009, perfectamente renovable vía sumisión tácita posterior (Pesce, 2013. p. 143) $)^{73}$. No parecía entenderlo así la Propuesta de Reglamento de alimentos, cuando

\footnotetext{
70 En la práctica, SAP Barcelona 15/9/2004 (JUR 2004\292863); o SAP Santa Cruz de Tenerife 13/3/2012 (AC 2012\765).

${ }^{71}$ En la práctica, véase la Sent. AG Flensburg 24/7/2014 (en Ludwig, I., 2020), que se declara competente para reducir la deuda alimenticia que el padre, deudor, debe a la hija acreedora de alimentos que reside habitualmente en Dinamarca; a la hija, que en el momento de la disputa se encuentra temporalmente en Alemania con su madre, se le notifica la demanda y comparece ante el Tribunal alemán solicitando la desestimación de la demanda sin impugnar la competencia del juez germano. La competencia objetiva correspondería a los Tribunales daneses con base en la residencia habitual de la acreedora (art. 3 R. 4/2009), siendo competentes finalmente los Tribunales del Amtsgericht Flensburg atendiendo al art. 5. R. 4/2009, sin necesidad de justificarlo en otra circunstancia (p.e.: la ubicación de la hija en la residencia alemana de la madre) distinta del comportamiento procesal de la acreedora. También, Sent. Oberlandesgericht Stuttgart 17/1/2014 (Zeitschrift für das gesamte Familienrecht, 2014, pp. 850-852), competente respecto de una solicitud de modificación de la pensión alimenticia a favor de dos menores con residencia habitual en Turquía, decidida originalmente en instancia cuando los niños vivían, al igual que el padre, en Alemania. Trasladados los menores a Turquía un año más tarde, el padre reclama ante el Amtsgericht Wangen para obtener la reducción de los alimentos, compareciendo los acreedores ante este Tribunal sin impugnar la competencia y alegando contra el fondo, competentes por la sumisión tácita del art. 5 R. 4/2009, en detrimento, posiblemente, si así lo estimaba el Derecho procesal turco, de la competencia de los Tribunales turcos (al respecto, véase Ricciardi, 2021, p. 613, cuando alude a este caso, refiriéndose a la intención de los acreedores de eludir la jurisdicción turca con esta sumisión tácita a favor de los Tribunales alemanes). Sobre toda esta práctica alemana, Ricciardi, 2021, pp. 613-614.

72 Véase las Conclusiones del Abogado General en la STJUE 29/7/2019, As. C-468/18, R, cuando estima que "debe precisarse que el artículo 5 de dicho Reglamento, invocado por el órgano jurisdiccional remitente debido a la comparecencia del demandado, no está destinado a aplicarse sobre la base de que establece un criterio de competencia aplicable en caso de falta de competencia del juez ante el que se interpone la demanda. A este respecto, el litigio principal ilustra perfectamente el hecho de que, cuando el juez es competente atendiendo a la residencia habitual del demandado, el criterio basado en su comparecencia personal ante el órgano jurisdiccional que conoce del asunto sin impugnar la competencia de este no reviste mayor interés" (ap. 45 y 46). No obstante, Mãculescu, Filip Radu \& George, 2016, párr. II.2.1.5, que entienden que un Tribunal de un Estado UE (rumano, desde la óptica de su trabajo) que se enfrenta a una demanda relativa a la pensión alimenticia respecto de los hijos menores y no competente por razón de responsabilidad parental (art. 3.d R. 4/2009), debería declararse de oficio no competente, aun cuando la comparecencia sin impugnación por parte del demandado del art. 5 R. 4/2009, dado que, a su juicio, la naturaleza de este tipo de reclamaciones resulta intrínsecamente vinculado a procedimientos en materia de responsabilidad parental.

${ }^{73}$ También, Queirolo \& Schiano di Pepe, 2008, p. 382, en este sentido y comentando la intención original de la Comisión, que el Consejo no aceptó, de no permitir el juego de la sumisión tácita en alimentos en la existencia de un acuerdo anterior.
} 
estimaba, a diferencia del texto actual, que no recoge este inciso, que "esta regla no será aplicable... si existe otro órgano jurisdiccional exclusivamente competente en virtud del artículo 4"74.

Téngase en cuenta, además, que el art. 5 R. 4/2009 no opera con los límites que impone el art. 4 R. 4/2009: libertad de elección tácita, ausente la exigencia de vinculación objetiva del órgano jurisdiccional tácitamente seleccionado con acreedor y/o deudor de alimentos, frente al juego restrictivo de la autonomía de la voluntad expresa. O, lo que es lo mismo, cabe el ejercicio de la sumisión tácita en materia de obligaciones alimenticias aun cuando este juego se halle restringido en lo que a sumisión expresa se refiere, lo que implica la posibilidad de hacer competentes tácitamente a Tribunales de un Estado miembro distintos a los seleccionables a partir del art. 4 R. 4/2009, esto es, no cabe una sumisión tácita limitada sólo a aquellos órganos jurisdiccionales seleccionables para la sumisión expresa (Villata, 2001, p. $751)^{75}$.

\subsection{Sumisión tácita y obligaciones alimenticias a} menores

Más dudas, en cambio, a la hora de decidir si la sumisión tácita, a diferencia también de la sumisión expresa, de operatividad limitada respecto de alimentos para menores, tiene proyección sobre este colectivo. La respuesta parece positiva. En tanto que nada se dice en el art. 5 R. 4/2009, no parece haber limitación a la autonomía de las partes, extendiéndose la prórroga tácita de la competencia también a las disputas de alimentos relativas a menores de 18 años (Ricciardi,
2021, p. 613; Abendroth, 2014, p. 468 y bibliografía allí referida; Volkova, 2017, p. 557, nota 43). Sigue así la línea de otras normativas que, si bien restringen total o parcialmente el ejercicio de la sumisión expresa, mantienen plenamente operativa la sumisión tácita, como es el caso, por ejemplo, de los foros relativos a materia laboral o de consumo del Reglamento 1215/2012 ${ }^{76}$. No recoge tampoco el art. 5 R. 4/2009 otras formas menos directas de protección de la parte débil en su posición de demandado, al estilo del art. 26 R. 1215 (Ricciardi, 2021, p. 613). Recuérdese que este precepto, en aquellos casos en los que el demandado es el tomador del seguro, el asegurado, un beneficiario del contrato de seguro, la persona perjudicada, el consumidor o el trabajador, exige al órgano jurisdiccional que se asegure, antes de asumir la competencia por sumisión tácita, "de que se ha informado al demandado de su derecho a impugnar la competencia del órgano jurisdiccional y de las consecuencias de comparecer o no". Aunque la ausencia de una cautela semejante en el Reglamento 4/2009 facilita un desarrollo más rápido de la controversia, se corre el riesgo de no garantizar protección suficiente a la parte demandada que lleva a cabo un comportamiento constitutivo de una sumisión tácita sin un conveniente asesoramiento legal y, con ello, sin garantía de una aceptación consciente de la jurisdicción (Walker, 2015, p. 66; Ricciardi, 2021, p. 613$)^{77}$. Más probable respecto de aquella parte de la relación alimenticia más vulnerable y con menor poder adquisitivo. A nuestro juicio, su posición se vería más protegida de exigir el legislador una cautela en la sumisión tácita semejante a la existente en el art. $26 \mathrm{R}$. 1215 (Walker, 2015, p. 66), que, por otro lado, tampoco está prohibida.

\footnotetext{
${ }^{74}$ Véase el art. 5 de la Propuesta de Reglamento del Consejo relativo a la competencia, la ley aplicable, el reconocimiento y la ejecución de las resoluciones y la cooperación en materia de obligaciones de alimentos (COM [2005] 649 final).

${ }^{75}$ En la práctica, véase STJCE 20/5/2010, As. C-111/09, Ceská podnikatelská pojišt'ovna as, Vienna Insurance Group v. Bilas, admitiendo el juego de la sumisión tácita en una materia (esta vez, seguros) donde el legislador limita el juego de la sumisión expresa.

${ }^{76}$ El Reglamento 1215/2012 restringe el ejercicio expreso de la autonomía de la voluntad entre empresario y trabajador con la intención de proteger la posición más débil de este último, que se manifiesta básicamente antes de la posibilidad de un litigio con el empleador. Las posiciones de ambas partes se igualan una vez que surge la controversia. Por ello, el legislador europeo, que admite el juego igualitario de la sumisión expresa posterior al nacimiento del litigio, no se opone al libre juego de la sumisión tácita. Sobre ello, Virgós y Garcimartín, 2007, pp. 296-297 y p. 306, respecto de la sumisión tácita.

77 También, Widiez, 2019, párr. 192, calificando de sorprendente esta ausencia de cautelas participando como lo hace una parte débil.
} 
En cualquier caso, a pesar de la ausencia en la sumisión tácita del principio de favor creditoris presente en la sumisión expresa y en el resto de los foros objetivos del Reglamento 4/2009, es cierto que conceder al acreedor un foro a mayores de los que ya dispone puede resultarle beneficioso, sobre todo si no le interesa el foro de su residencia habitual y cuando suele ser el acreedor la parte que en la práctica hace valer la posibilidad de sumisión tácita desde su posición de demandado ${ }^{78}$.

\section{Referencias bibliográficas}

Abendroth, M. (2014). Choice of Court in Matters Relating to Maintenance Obligations. En Beaumont, P., Hess, B., Walker, L. \& Spancken, S. (eds.). The Recovery of Maintenance in the EU and Worldwide (pp. 459-471). OxfordPortland: Hart Publishing.

Álvarez González, S. (2009). El Reglamento 4/2009/CE sobre obligaciones alimenticias: cuestiones escogidas. Diario La Ley (31 de julio de 2009), 7230, 1-21.

Ancel, B. \& Muir-Watt, H. (2010). Aliments sans frontières. Le règlement CE n 4/2009 du 18 décembre 2008 relatif à la compétence, la loi applicable, la reconnaissance et l'exécution des décisions et la coopération en matière d'obligations alimentaires. Revue critique de droit international privé, 3, 457-484.

Andrae, M. (2010). Art. 4. En Rauscher, T. (ed). Kommentar zum Europdischen Zivilprozess- und Kollisionsrecht EuZPR/ EuIPR. Munich: Sellier European Law Publishers.

Arenas García, R. (2017). Principios inspiradores del sistema actual de competencia judicial internacional en materia de persona y familia. En Guzmán Zapater, M. y Esplugues Mota, C. (dirs.). Persona y familia en el nuevo modelo español de Derecho internacional privado (pp. 21-50). Valencia: Tirant lo Blanch.

Bambust, I. (2009). Le règlement européen 4/2009 en matière d'obligations alimentaires. Journal des tribunaux, 6356, 381-392.

Beaumont, P.R. (2020). Interaction of the Brussels Ila and maintenance regulations with (possible) litigation in non-EU states including Brexit implications. En Viarengo, I. \& Villata, F.C. (eds.). Planning the future of cross border families: a path through coordination (pp. 331-346). Oxford, London, New York, New Delhi, Sydney: Hart.

Beaumont, V.P. (2009). International Family Law in Europe - The Maintenance Project, The Hague Conference and the EC: A Triumph of Reverse Subsidiarity. Rabels Zeitschrift für ausländisches und internationales Privatrecht, 73, 509-546.

Bonomi, A. (2007). Informe explicativo al Protocolo de La Haya de 23 de noviembre de 2007 sobre la ley aplicable a las obligaciones alimenticias. Conferencia de La Haya de Derecho Internacional Privado. Recuperado de: https:// assets.hcch.net/docs/84e93f6d-87ed-4928-8c65-13a3350ab23f.pdf [fecha de consulta: 26 de octubre de 2021] .

Borrás, A. \& Degeling, J. (2007). Informe explicativo del Convenio de 23 de noviembre de 2007 sobre Cobro Internacional de Alimentos para los Niños y otros Miembros de la Familia. Conferencia de La Haya de Derecho Internacional Privado. Recuperado de: https://assets.hcch.net/docs/70bf2354-6539-4a1a-b7da-a257b42bd940. pdf [fecha de consulta: 26 de octubre de 2021].

\footnotetext{
${ }^{78}$ Ricciardi, 2021, pp. 613-614, en este sentido, aludiendo, además, al caso ya referido de la Sent. Oberlandesgericht Stuttgart 17/1/2014 (Zeitschrift für das gesamte Familienrecht, 2014, pp. 850-852), posiblemente más ventajosa para los acreedores de alimentos la jurisdicción alemana que la turca.
} 
Calvo Caravaca, A.L. y Carrascosa González, J. (2018). Derecho internacional privado (18ª ed.). Granada: Comares. Castellaneta, M. \& Leandro, A. (2009). II regolamento CE n. 4/2009 relativo alle obbligazioni alimentari. Le nuove leggi civili commentate, 1051-1111.

Castellanos Ruíz, E. (2017). Derecho de alimentos. Aspectos internacionales y transfronterizos. Valencia: Tirant lo Blanch. Cheshire, North \& Fawcett (2017). Private international law (15a ed.). Oxford: Oxford University Press.

Corrao, M. E. (2011). II Diritto Internazionale Privato e Processuale Europeo in materia di obbligazioni alimentari. Cuadernos de Derecho Transnacional, 3 (1), 118-143.

Deschamps, M. (2011). Le règlement européen 4/2009 relatif aux aliments: Tentative de simplification de la résolution des litiges transfrontières en matière d'obligations alimentaires. Revue trimestrielle de droit familial, 4, 801-832.

Despina, M. \& Rodriguez, R. (2009). The Revised Lugano Convention from a Swiss Perspective. European Business Law Review, 20, 579-590.

Dicey, Morris \& Collins (2012) The Conflict of Laws (15a ed.). London: Sweet and Maxwell, Thomson Reuters.

Dickinson, A. \& Lein, E. (eds.) (2015). The Brussels I Regulation Recast. Oxford: Oxford University Press.

Domej, T. (2011). Art. 64. En Dasser, F. \& Oberhammer, P. (eds.), Lugano-Übereinkommen (2ª ed.) (pp. 940-948). Bern: Stämpfli Verlag.

Dutta, A. (2017). Domicile, habitual residence and establishment. En Basedow, J., Rühl, G., Ferrari, F. \& De Miguel Asensio, P. (eds.) Encyclopedia of Private International Law. (pp. 555-561). Cheltenham-Northhampton: Edward Elgar Publishing.

Fernández Rozas, J.C. y Sánchez Lorenzo, S. (2020). Derecho internacional privado (11ª ed.). Madrid: Civitas, Thomson Reuters.

Ferrand, F. (2011). The Council Regulation (EC) No 4/2009 of 18 December 2008 on jurisdiction, applicable law, recognition and enforcement of decisions and cooperation in matters relating to maintenance obligations. En Campuzano Díaz, B., Czepelak, M., Rodríguez Benot, A., \& Rodríguez Vázquez, M.A. (coords.) Latest developments in EU private international law (pp. 83-111). Cambridge: Intersentia.

Gandía Sellens, A., Faucon Alonso, A. \& Siaplaouras, P. (2020). Jurisdiction. En Viarengo, I. \& Villata, F.C. (eds.), Planning the future of cross border families: a path through coordination (pp. 163-202). Oxford, London, New York, New Delhi, Sydney: Hart.

Garau Sobrino, F. (2011). Las fuentes españolas en materia de obligaciones alimenticias. ¿Hacia un Derecho internacional privado extravagante? Cuadernos de Derecho Transnacional, 3 (2), 130-144.

Garcimartín Alférez, F.J. (2015). La competencia judicial internacional en la reforma de la Ley Orgánica del Poder Judicial. Diario La Ley (28 de septiembre de 2015), 8614, 1-8.

Gaudemet-Tallon, H. (2001). Le Reglement n 1347/2000 du Conseil du 29 mai 2000: "Compétence, reconnaissance et exécution des décisions en matiere matrimoniale et en matiere de responsabilité parentale des enfants communs". Journal du Droit International, II, 381-430.

Gaudemet-Tallon, H. (2015). Compétence et exécution des jugements en Europe (matières civile et commerciale: Règlements 44/2001 et 1215/2012, Conventions de Bruxelles 1968 et de Lugano 1988 et 2007) (5ª ed.). Paris: LGDJ.

Hellner, M. (2008). The Maintenance Regulation: A Critical Assessment of the Commission's Proposal. En European Challenges in Contemporary Family Law (pp. 343-378). Antwerp, Oxford, Portland: Intersentia,

Jiménez Blanco, P. (2017). Alcance de la autonomía de la voluntad en los procesos sobre persona y familia. En Esplugues Mota, C. y Guzmán Zapater, M. (dirs.). El derecho internacional privado de la familia (pp. 51-74). Valencia: Tirant lo Blanch.

Keyes, M. \& Brooke, A. M. (2015). Jurisdiction agreements: exclusive, optional and asymmetrical. Journal of Private International Law, 11 (3), 345-378. 
Kohler, C. (2008). Le nouveau régime transfrontalier des obligations alimentaires en Europe: interrogations sur le règlement (CE) n 4/2009 du Conseil. Annuaire de droit européen, 1175-1185.

Kostkiewicz, J. K. \& Eichenberger, M. (2015). International Maintenance Law in Legal Relations between Switzerland and the EU. Comparative Law Review, 20, 14-31. Recuperado de: http://apcz.umk.pl/czasopisma/index.php/ CLR/article/view/CLR.2015.009 [fecha de consulta: 26 de octubre de 2021].

Lipp, V. (2012). Parteiautonomie im Internationalen Unterhaltsrecht. En Verbeke, A., Scherpe, J., Declerck, C., Helms, T., \& Senaeve, P. (eds.). Confronting the Frontiers of Family and Succession Law, Liber Amicorum Walter Pintens, vol I (pp. 847-866). Cambridge, Antwerpen, Portland: Intersentia.

Lipp, V. (2013). En Rauscher, T. (ed.). Münchener Kommentar zum FamFG (2a ed.). Munich: H. Beck.

Ludwig, I. (2020). Juris PraxisKommentar BGB. Herberger, M., Martinek, M., Rüssmann, H., Weth, S. \& Würdinger, M. (ed.). Saarbrücken: Juris.

Mãrculescu, R., Filip Radu, D. \& George, B. (2016). Dilemmas in applying Council Regulation No 4/2009 (safeguarding the creditors' rights). Themis Competition, International Judicial Cooperation in Civil Matters- European Family Law. Recuperado de: https://www.ejtn.eu/PageFiles/14775/Written\%20paper_Romania2.pdf [fecha de consulta: 26 de octubre de 2021].

Marino, S. (2009). II nuovo regolamento comunitario sulla cooperazione giudiziaria civile in materia di obbligazioni alimentari. La nuova giurisprudenza civile commentata, II, 599-614.

Moura Ramos, R.M. \& Rodríguez Benot, A. (2016). Evolución reciente del Derecho internacional privado de familia en los Estados miembros de la Unión Europea. Madrid: Fundación Coloquio Jurídico Europeo.

Nylund, A. (2019). Family Maintenance and Multi-Speed Integration: A Norwegian Perspective. En Nylund, A. \& Strandberg, M. (eds). Civil Procedure and Harmonisation of Law, The Dynamics of EU and International Treaties (pp. 209-230). Cambridge, Antwerp, Chicago: Intersentia.

Pesce, F. (2013). Le obbligazioni alimentari tra diritto internazionale e diritto dell'Unione Europea. Roma: Aracne.

Pocar, F. (2009). La disciplina comunitaria della giurisdizione in tema di alimenti: il Regolamento 4/2009. En Baruffi, C. \& Cafari Panico, R. (dirs.). Le nuove competenze comunitarie. Obbligazioni alimentari e successioni (pp. 3-15). Padova: Cedam.

Pocar, F. \& Viarengo, I. (2009). II Regolamento (CE) n. 4/2009 in materia di obbligazioni alimentari. Rivista di diritto internazionale privato e processuale, XLV, (4), 805-828.

Poillot-Peruzzetto, S. (marzo de 2009). Le règlement n. 4/2009 du Conseil du 18 décembre 2008 en matière d'obligations alimentaires. Dalloz. Répertoire de droit communautaire, 3-11.

Queirolo, I. \& Schiano di Pepe, L. (2008). Le obbligazioni alimentari nel diritto internazionale privato comunitario. En Lezioni di diritto dell'Unione Europea e relazioni familiari (pp. 365-401). Torino: Giappichelli.

Ricciardi, G. (2021). Le corti tedesche ed il Regolamento (CE) n. 4/2009 sulle obbligazioni alimentari. Cuadernos de Derecho Transnacional, 13 (1), 608-628.

Rodríguez Vázquez, M.A. (segundo trimestre 2020). El Reglamento (CE) 4/09 en materia de obligaciones de alimentos. Problemas de aplicación y soluciones del TJUE. La Ley (Derecho de familia), 26, 1-16.

Rodríguez Vázquez, M.A. (2010). La regulación del Reglamento 4/2009 en materia de obligaciones de alimentos: competencia judicial internacional, ley aplicable y reconocimiento y ejecución de sentencias. Revista electrónica de estudios internacionales (REEI), 19, 1-30.

Rodríguez Vázquez, M.A. (2011). Un nuevo instrumento para la reclamación internacional de alimentos: el Reglamento (CE) núm. 4/2009 del Consejo, de 18 de diciembre de 2008. Revista Aranzadi de Derecho Patrimonial, 26, 221233. 


\section{Javier Maseda Rodríguez}

Rueda Valdivia, R. (2013). Cambios en el sistema español de fuentes de Derecho internacional privado en materia de alimentos. En Vázquez Gómez, E.M., Adam Muñoz, M.D. y Cornago Prieto, N. (coords.). El arreglo pacífico de controversias internacionales (pp. 607-620). Valencia: Tirant lo Blanch.

Vargas Gómez-Urrutia, M. (2012). El cobro internacional de los alimentos. Reflejos del dispositivo protector del acreedor de alimentos en las normas del Reglamento (CE) 4/2009. Revista de Derecho de la Unión Europea, 22, pp. 99-118.

Vargas Gómez-Urrutia, M. (2018). Litigios sobre obligación de alimentos. Normas de competencia y problemas procesales en el Reglamento 4/2009. En Guzmán Zapater, M. y Herranz Ballesteros, M. (dirs.) Crisis matrimoniales internacionales y sus efectos (pp. 317-352). Valencia: Tirant lo Blanch.

Vassalli di Dachenhausen, T. (2012). Qualche considerazione sull'autonomia delle parti nel regolamento comunitario 4/2009 in materia di obbligazioni alimentari. Diritto del commercio internazionale, 361-370.

Villata, F.C. (2011). Obblighi alimentari e rapporti di famiglia secondo il regolamento $n^{\circ} 4 / 2009$. Rivista di Diritto Internazionale, 3, 693-776.

Villata, F.C. \& Válková, L. (2020). Choice of court and choice of law clauses. En Viarengo, I. \& Villata, F.C. (eds.) Planning the Future of Cross Border Families (A Path Through Coordination) (pp. 625-798). Oxford, London, New York, New Delhi, Sydney: Hart.

Virgós Soriano, M. y Garcimartín Alférez, F.J. (2007). Derecho procesal civil internacional. Litigación internacional (2a ed.). Cizur Menor (Navarra): Thomson, Civitas.

Volkova, L. (2017). The interplay between jurisdictional rules established in the EU legal instruments in the field of family law: testing functionality through simultaneous application with domestic law. Cuadernos de Derecho Transnacional, 9 (2), 551-568.

Walker, L. (2015). Maintenance and child support in private international law. Studies in private international law. Oxford: Hart Publishing.

Widiez, G. (2019). Les obligations alimentaires à caractète international (Tesis). Universidad de Lille. 